\title{
STANDARDS AND RELATED REGULATIONS IN INTERNATIONAL TRADE: A MODELING APPROACH
}

\author{
Mattias Ganslandt \\ James R. Markusen \\ Working Paper 8346 \\ http://www.nber.org/papers/w8346
NATIONAL BUREAU OF ECONOMIC RESEARCH
1050 Massachusetts Avenue
Cambridge, MA 02138
June 2001

This paper was prepared for a World Bank project on Standards. The views expressed herein are those of the authors and not necessarily those of the National Bureau of Economic Research or the World Bank.

(C) 2001 by Mattias Ganslandt and James R. Markusen. All rights reserved. Short sections of text, not to exceed two paragraphs, may be quoted without explicit permission provided that full credit, including (C) notice, is given to the source. 
Standards and Related Regulations in International Trade: A Modeling Approach

Mattias Ganslandt and James R. Markusen

NBER Working Paper No. 8346

June 2001

JEL No. F01, F02

\section{ABSTRACT}

Standards and technical regulations which govern the admissibility of imported goods into an economy raise costs of exporters entering new markets, and may have a particularly high impact on firms seeking to export from developing countries. Yet standards may also have a positive side, such as certifying product quality and safety for the consumer. This paper suggests approaches to modeling standards and technical regulations, with a particular concern that these approaches are at least potentially implementable in an applied general-equilibrium model with real data.

Mattias Ganslandt

Research Institute of Industrial Economics

Box 5501

SE-114 85 Stockholm

Sweden

mattiasg@iui.se
James R. Markusen

Department of Economic University of Colorado

Boulder, CO 80309-0256 and NBER

james.markusen@colorado.edu 


\section{Introduction}

Standards and technical regulations have assumed increased importance in the tradepolicy agenda. Possibly, this is because they have become quanitatively more important and burdensome, or possibly they are simply relatively more important as traditional trade barriers such as tariffs and quotas decline in importance. In either event, there seems to be a case for closer examination and more formal modeling of standards as they impact on trade and national welfare.

Standards and technical regulations are often portrayed as barriers to trade that restrict competition in the local economy by raising costs to foreign suppliers. The idea that standards can constitute an anti-competitive and protectionist device seems obvious. Yet it is clear that they may also have benefits, not just to domestic consumers but also to foreign suppliers. If a standard certifies a product as safe, healthy, compatible with complementary inputs such as the power supply, etc., such certification can raise consumer demand for the imports, possibly resulting in increased profits to foreign firms in spite of higher costs.

The purpose of this paper is to suggest approaches to formally modeling standards in ways that are potentially implementable on real data. For all the ideas developed here, we present numerical results from simple simulation models (i.e., with minimum dimensionality and simple made-up data). The advantage of this approach is that (a) we see that the idea is at least potentially operational, and (b) clearly see the effect of a standard in a model where all extraneous influences are eliminated. With respect to the latter, we will use very simple numerical general-equilibrium models in which countries have identical relative productivities (technologies) across sectors, identical relative factor endowments, and constant returns to scale 
so as to eliminate traditional comparative-advantage motives for trade. We assume a sector with imperfectly competitive firms, possibly a valid representation of many manufacturing sectors, but not necessarily for agriculture (although in the latter case, often the exporting firms as opposed to farmers are indeed quite few in number). But regardless of the validity or generality of this approach, the techniques for modeling the standards themselves can be applied to any applied-general equilibrium model. One advantage of the imperfect-competition approach is that it quickly identifies conflicts or complementarities between producer and consumer interests, both within and between countries.

Sections 2, 3, and 4 use a two-good, two-factor, two-country, general-equilibrium model in which countries have identical relative productivities across sectors and relative factors endowments. ${ }^{1}$ But in general we assume that one country is considerably larger than the other, either because of endowment size or (sector neutral) technical superiority, trying to capture one notion of rich/big versus poor/small countries. Each country has a fixed number of imperfectly competitive firms in the $\mathrm{X}$ sector.

In section 2, we show how to model a purely cost-increasing standards; that is, there is no beneficial effect from the standard. Not surprisingly, a standard imposed by one country tends to benefit producer interests at the expense of consumer interests. An important result, but possibly also not surprising, is that the small country cannot win a "standards' war" in which both countries impose cost-increasing standards on imports, analogous to a tariff war in traditional trade theory. Both producers and consumers may lose in the small country. Thus an

${ }^{1}$ By identical "relative" technologies or productivities across sectors we mean that there is no Ricardian comparative advantage. One country could be uniformly more advanced in all sectors. 
international code that restricts the use of purely "harassment" standards (e.g., multiple inspection requirements) aids the small/poor country and may even win support from smallcountry import-competing producers.

Section 3 considers a standard imposed only by the big/rich country. In addition to imposing a cost on exporters from the small/poor country however, the standard also creates an increased willingness-to-pay by the large/rich country's consumers for the small-country's good. We model this as sliding the large-country consumer's indifference curve along a budget line so that, for example, at constant prices the consumer now chooses 2.5 units of each country's good instead of four units of the large-country's good and 1 unit of the small-country's good. Of course, prices do change in response to the standard. Simulation results illustrate the tradeoff between the cost and willingness to pay from the point of view of small-country firms and consumers.

Section 4 is identical to section 3 except that we assume that the standard creates a fixed cost for the small country's firms. For example, a new design might be required, but once this is created the marginal cost of production is unchanged. The interesting thing about this case is that, when there are multiple firms, there may be multiple equilibria. With a coordination problem (or free-rider problem) among firms, there may be one equilibrium in which no firm exports, and one in which there are substantial exports. Thus standards of this type create a role for the government in the non-standard-imposing country to oppose the standard or to coordinate compliance and compliance costs.

Section 5 presents an analysis in which a standard can change the complementarity or substitutability between products. This is a rather tricky problem, so we use a closed-economy 
model in which there are two sets of firms. Much of the problem lies not so much with the idea of changing the shape of isoquants, as with there interpretation of welfare changes. In a traditional Dixit-Stiglitz formulation for example, poor substitutability is a source of welfare gains (love of variety), so reducing substitutability reduces welfare other things equal. This is balanced in our model with variable markups (unlike the usual large-group monopolisticcompetition model) by a pro-competitive effect arising from increased substitutability. Great care is needed in interpreting the former effect.

We examine two cases in section 5, the first one being a standard which increases substitutability between goods. We are thinking here of IBM and Apples as being made so that they run the same software so that they appear to be better substitutes from the consumer's point of view. A result in this case is that producer and consumer interests may conflict, with consumer's wanting a common standard and producers opposing it since the standard is procompetitive.

In the second case, we consider a standard which makes products better complements, and we try to carefully state how this is different from making them poorer substitutes. Here we are thinking about a computer and a telephone, for example. If they can be made to work together, the consumer's willingness to pay for one of each might increase, while the demand price for one of either individually might not change. The result here is that both consumers and producers may benefit from increased complementarity. Thus standards which make different products work together might receive stronger political support than ones which make products more similar.

In section 6, we consider the idea that standards may act as a market-segmentation device, 
which prevents arbitrage and parallel trade in oligopolistic markets. In the automobile industry, for example, country-specific emission, safety and damageability standards prevent non-auto firms and consumers from arbitraging products from one market to another. In many situations this might not be an issue for developing countries. But there are instances in which a country could either be helped or hurt by restrictions on arbitrage. If arbitrage is not possible, a small/poor country could benefit if optimal pricing by a pharmaceutical company dictated a lower price in that country (knowing that the product could not be shipped back to the highincome country). But in other cases optimal pricing, possibly in the presence of high distribution costs, might imply higher prices in the small market.

All of the models we develop are coded in Rutherford's MPS/GE solver, now a subsystem of GAMS. Programs are attached. These illustrate that all of the models used here are potentially implementable. However, great data difficulties remain before actual implementation. If standards are in place in observed data, the researcher needs to estimate a "shadow value" for the restriction, and this could be either positive or negative depending on whether or not an increased willingness to pay outweighs any increased costs from meeting the standard. But this can be done, just as many researchers have estimated the shadow rents from quotas, domestic content restrictions, and so forth. 


\section{2. $\quad$ Standards as Real Trade Costs}

In this section, we adopt a very simple "first pass", and assume that standards are simply trade costs. We implicitly assume that firms of one country make or have made some investment in their own country's standard, but must incur a second investment to serve the foreign market. The standards of the two countries are simply different, neither is better or worse than the other. Any exports to a country must meet the importing country's standard to be permitted to enter. An example that might come close is 110 volt versus 220 volt systems for small electrical appliances.

The model assume two goods, $\mathrm{X}$ and $\mathrm{Y}$, two factors, labor and capital ( $\mathrm{L}$ and $\mathrm{K}$ ), and two countries home and foreign ( $h$ and $f$ ). Throughout the paper, we will think of country $h$ as a large/rich developed country, and $\mathrm{f}$ as a smaller/poorer developing country. But, as noted in the introduction, we will assume no comparative advantage in the $\mathrm{X}$ versus the $\mathrm{Y}$ sector so as to focus on the essentials (country h may have a equal absolute advantage in both sectors). The Y sector produces a homogeneous good with constant returns to scale and perfect competition, while the $\mathrm{X}$ sector produces differentiated goods with imperfectly competitive firms. In order to see opposing or complementary effects on producers versus consumers, we assume a relatively "short run" analysis in which the number of X firms is fixed in each country.

Let $\mathrm{X}_{\mathrm{ji}}$ be the supply by a single firm in country $\mathrm{j}$ to the market in country $\mathrm{i}$. Welfare in country $i$ is given by

$$
U_{i}=Y_{i}^{1 / 2} U X_{i}^{1 / 2} \quad U X_{i}=A\left[n_{h} X_{h i}^{\beta}+n_{f} X_{f i}^{\beta}\right]^{1 / \beta} \quad \sigma=\frac{1}{1-\beta}
$$

where $n_{h}$ and $n_{f}$ are the number of firms (varieties) in countries $h$ and $f$ respectively. $\sigma$ is the elasticity of substitution between any two X goods (in this section we do not assume any 
"nesting": two goods from country $i$ have the same substitutabilitiy as one good from $i$ and one good from $\mathrm{j}$ ). The production function for $\mathrm{Y}$ in country $\mathrm{i}$ is given by

$$
Y_{i}=L_{i y}^{\gamma} K_{i y}^{1-\gamma}
$$

Production functions for $\mathrm{X}$ are identical across firms and countries. The production by a representative firm in country $i$ is given by

$$
X_{i}=L_{i x}^{\delta} K_{i x}^{1-\delta}
$$

$L$ and $K$ are in inelastic supply, so factor-market clearing requires that factor demands add up to total factor supplies in country i.

$$
L_{i}^{*}=L_{i y}+n_{i} L_{i x} \quad K_{i}^{*}=K_{i y}+n_{i} K_{i x}
$$

Firms in the $\mathrm{X}$ sector are imperfectly competitive. Let $\mathrm{p}_{\mathrm{ij}}$ denote the price for $\mathrm{X}$ of a firm producing in market $\mathrm{i}$ selling in market $\mathrm{j}$. Firms set markups $\mathrm{m}_{\mathrm{ij}}$ according to the formula

$$
p_{i i}\left(1-m_{i i}\right)=m c_{i}\left(w_{i}, r_{i}\right) \quad p_{i j}\left(1-m_{i j}\right)=\left(1+s_{j}\right) m c_{i}\left(w_{i}, r_{i}\right)
$$

where $m c_{\mathrm{i}}$ is the marginal cost of producing a variety $X_{\mathrm{i}}$ (an identical function across countries), and $w$ and $r$ are the prices of labor $(L)$ and capital $(K) . \mathrm{s}_{\mathrm{j}}$ is the cost of meeting country $\mathrm{j}$ 's standard when exporting from country i. Denote the elasticity of substitution among X varieties as $\sigma$. The Cournot markup formula for the markup of an individual firm located in market $i$ and selling in market $\mathrm{j}$ is given by (Lopez-de-Silanes, Markusen, and Rutherford, 1993).

$$
m_{i j}=\frac{1}{\sigma}+\left[1-\frac{1}{\sigma}\right] \frac{n_{i} X_{i j}}{n_{i} X_{i j}+n_{j} X_{j j}} \frac{1}{n_{i}}
$$

In the case of homogeneous goods where the elasticity of substitution is infinite, this reduces to the well-known equation that a firm's markup is its market share. 
This model can be implemented numerically as a complementarity problem: a set of inequalities with associated non-negative variables. There are 31 non-linear inequalities in this model. These are as follows:

$\underline{\text { Cost functions (complementary variables: outputs) }}$ Number

Y sector output in each country 2

$\begin{array}{ll}X \text { sector output in each country } & 2\end{array}$

Cost of supplying market i from market $\mathrm{j} \quad 4$

Production of utility for consumers in each country 2

Production of utility for "entrepreneurs" in each country 2

Market clearing equations (complementary variables: prices)

Market for good Y 1

Total output of $\mathrm{X}$ in each country 2

Supply of X from country i to country j

$\begin{array}{ll}\text { Labor market clearing in each country } & 2\end{array}$

$\begin{array}{ll}\text { Capital market clearing in each country } & 2\end{array}$

Income balance equations (complementary variable: the price of utility)

Income balance for consumers in each country 2

Income balance for entrepreneurs in each country 2

Auxiliary equations (complementary variable: markups)

Markup equation for producer in market i serving market $\mathrm{j} \quad 4$

These inequalities are solved numerically using Rutherford's MPS/GE for various values of the parameters, and the code is given in Appendix 1. 
Figures 1-3 give results from simulations of this model. Country h has $4 / 5$ of world income and country f has $1 / 5$. We can think this as endowment size differences and/or total factor productivity differences. Figures $1 \mathrm{~A}$ and $2 \mathrm{~B}$ give the effect of a standard $\mathrm{s}_{\mathrm{h}}$ on the profits and consumer real income (welfare) in country h (panel A) and in country f (panel B). Consumer welfare refers to total factor income divided by the consumer price index. Profits are markup revenues divided by the same price index (firm owners have the same tastes as factor owners). The cost of the standard on the horizontal axes is an ad valorem proportion on marginal production costs. Consumers in both countries are worse off by the standard, almost to the same extent in the two countries. Not surprisingly, profits increase substantially for firms in the large country and fall for the small-country firms. Thus the standard serves the political interest of the large-country firms at the expense of everyone else. ${ }^{2}$

Figures $2 \mathrm{~A}$ and $2 \mathrm{~B}$ show the effects of a standard imposed by the small country f. Effects on the large country $\mathrm{h}$ are shown in the top panel A and for the small country $\mathrm{f}$ in the bottom panel B. Results in the top panel are qualitatively similar to Figure 1, but far less significant quantitatively. The small country cannot hurt the large country very much. An interesting result occurs in the bottom panel, where the small-country's standard actually hurts its own firms up to the level of about 0.2. This appears to be a general-equilibrium effect, in that the small-countries restriction on imports from the large country causes the latter's firms to supply more to their own

\footnotetext{
${ }^{2}$ We have not shown aggregate welfare effects in the two countries to avoid reducing clutter and/or adding more diagrams. In the benchmarking of the model (Appendix 1), profits are $10 \%$ of total income (but this is not of course a constant). The large country does not benefit in aggregate from its own standard (Figure 1A). A 25\% rise in profits cannot compensate for a 5\% fall in consumer real income. In the simulations, neither country benefits from neither standard in aggregate.
} 
market, "crowding out" imports from the small country. ${ }^{3}$ For low levels of the restriction, this effect reduces profits of the small country's firms by more than it increases their profits from protection at home.

Figures $3 \mathrm{~A}$ and 3B show what happens when both countries impose the same ad valorem restrictive standard. Consumers in both countries are hurt, but they are hurt far more in the small country f (panel B) than in the large country h (panel A). Profits increase for firms in the large country even though they face an import barriers into country f. Profits for firms in the small country f fall up until a bilateral barrier of 0.2 and then begin to rise, but only recover their freetrade level at about a 0.5 barrier.

The message from Figures $3 \mathrm{~A}$ and $3 \mathrm{~B}$ is clearly that the small/poor country cannot win a "standards war". Such a war can only benefit firms in the large country. Conversely, an agreement to limit purely cost-increasing standards helps the small country most (although it helps large-country consumers as well). This result fits well with results on "tariff wars".

${ }^{3}$ This is a general-equilibrium effect that is missed in partial-equilibrium models. As output for supply to the small market falls for the large-country's firms, factor prices fall for the $\mathrm{X}$ industry in country $\mathrm{h}$. Thus marginal revenue (initially unchanged) exceeds marginal cost for sales to the h firms own market, and supply will increase. This doesn't happen in well known "strategic trade-policy" models with constant costs. 


\section{Standards which affect willingness to pay}

In many situations, it is surely not the case that standards are simply a cost-raising measure with no offsetting positive value. Surely consumers (through importers and wholesalers) put "certification value" on such things as health and safety standards. The difficulty is that one could imagine a whole portfolio of models to deal with these issues. Models could involve asymmetric information, markets-for-lemons problems and so forth. The purpose of this paper is to suggest simple and implementable ways to incorporate standards into numerical general-equilibrium models. Thus here we will take a very simple approach in which we model the "certification value" as an increased willingness to pay by consumers. The added amount that American consumers would be willing to pay for Mexican tomatoes if they are certified as healthy and safe by US standards is what we refer to as willingness to pay.

Unfortunately, that is not the end of the issue, since there are many ways to formally model an increased willingness to pay. What we are doing is altering the utility function, shifting an twisting an indifference curve between the domestic and imported product in some way.

Obviously, there are essentially infinitely many ways to do this. Considerable care is needed, in that different alternatives have quite different implications for welfare measures.

Figures 4A and 4B illustrate two possibilities. In Figure 4A, an increased willingness to pay for $\mathrm{X}_{\mathrm{f}}$ is modeled as simply a change in the ratio of $\mathrm{X}_{\mathrm{f}}$ to $\mathrm{X}_{\mathrm{h}}$ demanded at a constant price ratio, holding utility constant. $\mathrm{UX}^{0}$ represents the same utility level in the Figure. In Figure 4B, an increased willingness to pay is modeled by the shift shown in $\mathrm{UX}^{0}$ (again, the two curves give the same utility level). Consumers can now get the same utility level from less $\mathrm{X}_{\mathrm{f}}$ or alternatively are willing to pay more for (get more utility from) the same level of $\mathrm{X}_{\mathrm{f}}$. Note that there is a 
welfare difference between these two alternatives. With respect to Figure $4 \mathrm{~B}$, there is a new indifference curve tangent to the original budget line through $X^{1}$ to the north west of $X^{1}$ (if the elasticity of substitution between the two goods is greater than one) thus making it appear that the standards leads to a similar sliding along the original budget line as in Figure 4A. But if we did this this in Figure 4B, the new indifference curve on the original budget line would correspond to a higher level of utility, not the same level of utility as in Figure 4A.. Figure 4B could be thought of analogous to a technical improvement, while Figure 4A is not. It is certainly not clear which procedure is correct, but the modeler must remember that they are not the same.

In this section, we model increased willingness to pay as in Figure 4A, while we will use the procedure in Figure 4B in the next section. There is no good justification for this other than we want to show modelers how to do each in the simulation programs. Appendix 2 gives the model for Figure 4A, while Appendix 3 gives the model use the procedure in Figure 4B.

We retain the same model and calibration (Table 2) of the previous section. Assume that only the large/rich country imposes a standard. Figures 5A and 5B show the effects on the profits of the small country $f$ firms and on consumer real income respectively. The numbers on the "Willingness to Pay" axis are the share of X purchases by large country h's consumers that would go to the small country f's good if the prices of the two were the same. That is, the axis measures the large country h's demand share $X_{\mathrm{f}} /\left(\mathrm{X}_{\mathrm{h}}+\mathrm{X}_{\mathrm{f}}\right)$ at equal prices for the two goods (of course, equilibrium prices do not stay the same as we recalibrate country h's preferences.

The results in Figures 5A and 5B are not very surprising. They do make it clear that there is no conflict between the interests of small-country producers and consumers when it come to the standard imposed by the large-country. Effects on consumers are much smaller than on 
producers, which also makes sense. In any case, while there is no great insights here, we hope that this section nevertheless makes a contribution in terms of clarifying some issues and showing how these ideas can be implemented in an applied general-equilibrium model. 


\section{Standards impose a fixed cost of entry: multiple equilibria}

In many cases, it does not seem reasonable to assume that a standard imposes a constant ad valorem cost. It may require a redesign cost, after which the good can be produced at the old marginal cost. The new design created by this fixed cost can in turn be purely private, or it may be a non-excludable public good. The latter case is particularly interesting, and leads to different theoretical, modeling, and policy issues. One of these is the possibility of multiple equilibria, which will be the focus of this section. At a given fixed (e.g., redesign) cost needed to meet the large-country's standard, there may be two equilibria, one with zero exports from the small country and one with positive exports (and likely a third inbetween).

In this section, we use the same model and calibration (Table 2) of the previous two section. Appendix 3 shown how to model the standard as a fixed cost using MPS/GE. There is an "endogenous tax rate" on exports from country $\mathrm{f}$, and this tax rate is set be a constraint equation. A fixed rate is divided by the activity level of the exports, which is equal to one in the initial calibration. As exports go to zero, the ad valorem equivalent of the fixed cost goes to infinity.

Table 1 shows results for the model, where the benchmark values in the top row are all normalized to one. The fixed rate, denoted "cost" is initially zero, and willingness to pay ("wtp") equals 1.0. We report consumer real income (cons), profits of the local firms (profit), and aggregate welfare or real income (welf). The willingess to pay is modeled as in Figure 4B, where the numerical value in Table 1 is the ratio $X^{1} / X^{0}$ in Figure $4 B$.

The second set of numbers raises "cost" to 0.1 , so this would be an ad valorem rate of $10 \%$ at the initial activity level of 1.0 for exports to country h. There is no increased willingness 
to pay. We see that there are two equilibria, the first with positive exports and one with no exports. The former is roughly like results in Figures 1-3 except that the export activity level falls below one, meaning that the ad valorem equivalent is greater than $10 \%$. The no-exports equilibrium is very different. Country h firms get a large profit boost, while large-country consumers, small-country consumers, and small-country firms are worse off. Note that aggregate welfare falls in the large country h as well as in the small country $\mathrm{f}$.

The next two sets of results raise the wtp first to 1.1 and then to 1.25 in the last simulation. There are multiple equilibria in both cases. The no-export equilibria is the same in all cases, but we have reproduced the numbers anyway for easy comparison with the "interior" equilibrium with positive exports. For a wtp of 1.1 , and a cost of 0.1 , it is interesting to note that these values are close to offsetting in the results for the interior equilibrium for consumers and firms in both countries.

The final set of numbers with a wtp of 1.25 indicate that the standard significantly improves the welfare of country f's firms and consumers in the interior equilibrium. But the bad outcome remains a possibility. This kind of situation clearly calls for a more active policy in the small/poor country, in aiding industry to adapt to foreign standards. 


\section{Standards Alter the Substitutability / Complementarity between Products}

In this section, we will present a simple closed-economy general-equilibrium model in order to examine how standards might affect the relationship between different product types. Suppose that there are two goods, $X$ and $Y$, and two factors, $L$ and $K . X$ goods come in two types or standards, $X_{1}$ and $X_{2}$, these being imperfect substitutes. There may be several firms producing each standard, and the output of standard $X_{\mathrm{i}}$ by firm $\mathrm{j}$ is denoted $X_{\mathrm{ji}}$. There is a representative consumer who derives utility from $Y$ and a CES composite of $X_{1}$ and $X_{2}$, denoted $U X$.

$$
U=Y^{1 / 2} U X^{1 / 2} \quad U X=A\left[X_{1}^{\beta}+X_{2}^{\beta}\right]^{1 / \beta} \quad \sigma=\frac{1}{1-\beta} \quad X_{i}=\sum_{j} X_{j i}
$$

where $\sigma$ is the elasticity of substitution between goods of different standards. The production function for $\mathrm{Y}$ is given by

$$
Y=L_{y}^{\gamma} K_{y}^{1-\gamma}
$$

Production functions for $\mathrm{X}$ are identical across firms within and between types.

$$
X_{i j}=L_{i j x}^{\delta} K_{i j x}^{1-\delta}
$$

$L$ and $K$ are in inelastic supply, so factor-market clearing requires that factor demands add up to total factor supplies.

$$
L^{*}=L_{y}+\sum_{i} \sum_{j} L_{i j x} \quad K^{*}=K_{y}+\sum_{i} \sum_{j} K_{i j x}
$$

Firms in the $\mathrm{X}$ sector are imperfectly competitive. Firms of standard $\mathrm{j}$ set a markup mj according to the formula

$$
p_{x j}\left(1-m_{j}\right)=m c_{x j}(w, r)
$$

where $p_{\mathrm{xj}}$ is the price of standard $\mathrm{j}$, and $m c_{\mathrm{xj}}$ is the marginal cost of producing $x_{\mathrm{j}}$ (identical across standards), and $w$ and $r$ are the prices of labor $(L)$ and capital $(K)$. Let $\sigma_{\mathrm{w}}$ denote the elasticity of substitution within a firm type (e.g., between the products of two type- 1 firms) and $\sigma_{b}$ the 
elasticity of substitution between firm types (i.e., between the products of a type- 1 and a type- 2 firm). The Cournot markup formula for the markup of an individual type- $\mathrm{j}$ firm is given by (Lopez-de-Silanes, Markusen, and Rutherford, 1993).

$$
m_{j}=\frac{1}{\sigma_{w}}+\left[\frac{1}{\sigma_{b}}-\frac{1}{\sigma_{w}}\right] \frac{1}{n_{j}}+\left[1-\frac{1}{\sigma_{b}}\right] \frac{X_{j}}{X_{i}+X_{j}} \frac{1}{n_{j}}
$$

where $n_{j}$ is the number of type-j firms. In our case, goods of given standard are perfect substitutes, so $\sigma_{\mathrm{w}}$ is infinite. This simplifies the formula to

$$
\begin{aligned}
& m_{j}=\frac{1}{\sigma_{b}} \frac{1}{n_{j}}+\left[1-\frac{1}{\sigma_{b}}\right] \frac{s_{j}}{n_{j}} \quad s_{j}=\frac{X_{j}}{X_{i}+X_{j}} \\
& m_{j}=\left[\frac{1}{\sigma_{b}}+\left[1-\frac{1}{\sigma_{b}}\right] s_{j}\right] \frac{1}{n_{j}}=\frac{s_{j}}{n_{j}}+\left[1-\frac{s_{j}}{n_{j}}\right] \frac{1}{\sigma_{b}}
\end{aligned}
$$

where $s_{\mathrm{j}}$ is the share of all type-j firms in total $X$ output. Thus $s_{\mathrm{j}} / n_{\mathrm{j}}$ is the overall $X$ market share of one type-j firm. The markup is increasing in a firm's market share, and decreasing in the elasticity of substitution between standards.

Consider first the situation in which a standard improves the substitutibility between products $X_{1}$ and $X_{2}$ (e.g., PC and MAC computers). The situation as we will model it is shown in Figures $6 \mathrm{~A}$ and $6 \mathrm{~B}$. Two indifference curves for a given level of $\mathrm{UX}$, denoted $\mathrm{UX}_{0}$, are shown in Figure 6A. The curve without the standard has a low elasticity of substitution, while that with a standard has a higher elasticity of substitution. In order for the two curves to correspond to the same value of $U X$ (point $X^{0}$ gives the same value of output $U X$ ), the constant term $A$ in the 
second equation of (1) must be adjusted to offset the change in $\beta$ (equal to $1 /(1-\sigma)$ ). If $\beta$ is increased from $\beta_{0}$ to $\beta_{1}$, the intercept $A$ must be recalculated as follows.

$$
U X^{0}=A_{0}\left[\left(X_{1}^{0}\right)^{\beta_{0}}+\left(X_{2}^{0}\right)^{\beta_{0}}\right]^{1 / \beta_{0}}=A_{0} 2^{1 / \beta_{0}} X^{0}=A_{1} 2^{1 / \beta_{1}} X^{0} \quad X^{0}=X_{1}^{0}=X_{2}^{0}
$$

implying,

$$
A_{1}=A_{0} 2^{\left(1 / \beta_{0}-1 / \beta_{1}\right)}
$$

This compensating change in $A$ to offset the change in $\beta(\sigma)$ means that the output $U X^{0}$ can still be produced from equal inputs of $X_{1}$ and $X_{2}\left(X^{\mathrm{O}}\right)$. Nevertheless, we might also believe that in a wide range of specific cases, the standard may also affect the cost of production or alternatively the consumers' willingness to pay. Thus the standard may also move the $\mathrm{UX}^{0}$ isoquant in or out as shown in Figure 6B. Holding $\mathrm{UX}^{0}$ constant, movement of this isoquant inward can be thought of

as reduced costs of production. Alternatively, we can think of this as an increased willingness to pay: the consumer is willing to pay the same amount derived from a smaller quantity of inputs.

In either case, this can be represented by a further change in $A$. So let us think of the standard has having an effect on $\beta(\sigma)$ and A. The change in $A$ comes in two parts: the first is a compensating change to the change in $\beta(\sigma)$ so that output $U X^{0}$ can still be produced from equal inputs of $X_{1}$ and $X_{2}\left(X^{0}\right)$. Then a subsequent change in $A$ shifts the $U X^{0}$ isoquant in or out as in Figure 6B. From this point on, we will refer to only this second change as the change in cost, and/or change in willingness to pay.

An important point in this model is that the increased elasticity of substitution between 
$\mathrm{X} 1$ and $\mathrm{X} 2$ leads to a pro-competitive effect via a decrease in markups. Referring back to equation (14), we see that an increase in $\beta(\sigma)$ leads to a fall in the markup ( $s / n$ must be less than one). $s$ is constant at $1 / 2$ (the two product groups are symmetric), and here we are holding the number of firms $(n)$ fixed. With no change in willingness to pay, this should imply an increase in consumer welfare and a fall in producer profit. General intuition suggests that overall welfare should rise with the increase in $\beta(\sigma)$.

In alternative situations, we might expect that standards should make products better complements Two products might have quite different functions, but if a common standard allows them to work together, then consumers may be more inclined to buy both. If telephones (the phone system) and computers can be made to work together, they become compelements. This situation is modeled in Figures $7 \mathrm{~A}$ and $7 \mathrm{~B} . \quad U X^{0}$ with no standard has a relatively high elasticity of substitution. If the two products can be made to work together (e.g., the compatibility of the phone system and computers allowed for the development of the internet), then they become complements. Specifically, assume that the consumer's willingness to pay for either a phone or a computer (not both) does not change. Thus the endpoints of the $U X^{0}$ isoquant in Figure 6A do not change. But the consumer may now be willing to pay more for both products together. In Figure $7 \mathrm{~A}$, the point on the $45^{0}$ line with the standard $\left(\mathrm{X}^{1}\right)$ lies inside the original no-standard point $\mathrm{X}^{0}$. Let $\alpha<1$, denote the ratio $\mathrm{X}^{1} / \mathrm{X}^{0}$ in Figure $7 \mathrm{~A}$ (note this ratio is only value on the $45^{0}$ line, it goes to zero near the axes). A given $\alpha$ implies a recalibrated elasticity of substitution. The intercept of the production function $A$ does not change (the with and without standards isoquants go through the same points on the axes). For a given $\alpha$, the new 
value of $\beta(\sigma)$ is found by solving the following equation.

$$
\begin{aligned}
& U X^{0}=A 2^{1 / \beta_{0}} X^{0}=A 2^{1 / \beta_{1}} \alpha X^{0} \quad X^{0}=X_{1}^{0}=X_{2}^{0} \\
& 2^{1 / \beta_{0}}=2^{1 / \beta_{1}} \alpha \quad \frac{1}{\beta_{0}} \ln 2=\frac{1}{\beta_{1}} \ln 2+\ln \alpha \\
& \beta_{1}=\left[\frac{1}{\beta_{0}}-\frac{\ln \alpha}{\ln 2}\right]^{-1} \quad \sigma_{1}=\frac{1}{1-\beta_{1}}
\end{aligned}
$$

Thus a higher $\alpha\left(\mathrm{X}^{1} / \mathrm{X}^{0}\right)$ implies a lower $\beta(\sigma)$ in Figure 7A.

As in our previous example, the standard may also change the consumer's willingness to pay or the costs of production. Thus we might again want to consider changes in $A$, shifting the quantities of $X_{1}$ and $X_{2}$ necessary to acheive level $U X^{0}$. This is shown in Figure 7B. The $U X^{2}$ isoquant corresponds to no change in $A$.

Referring back to the markup equation (14), we see that the increased complementarity should raise the equilibrium markup. Thus the changes shown in Figures 7A and 7B with no change in willingness to pay, should improve producer profit. We would also expect an increase in consumer welfare, although a very strong markup effect might reverse this. Baring the latter, it may be here that the consumer and producers' interests coincide in favor of the standard, unlike in the substitutes case with no change in willingness to pay.

Figures 3-5 present simulation results for this closed economy general-equilibrium model for increased substitutability (Figure 1). On one axis, we plot the elasticity of substitution between $X_{1}$ and $X_{2}$. The "no-standard" value is assumed to equal 0.5: the goods are poor substitutes in the absence of the standard. The other axis plots willingess to pay, parameter $A$ in 
(13), where the no-standard value is 1.0. Alternatively, we can think of this as an inverse cost measure, where the standard increases production costs. In the Figures, we allow for the possibility that the standard increases cost (decreases willingness to pay), such as isoquant $U X_{1}$ in Figure 6B. The model is calibrated so that there are five firms of each type active.

Figure 8A plots consumer welfare (real factor income) over a grid of values for $\sigma$ and $A$. We see a sharp increase in consumer welfare as $\sigma$ increase from 0.5 , but that this effect tapers off at about $\sigma=3$. Consumer welfare, on the other hand, is close to linear in willingness to pay, or cost decreases. Figure $8 \mathrm{~B}$ shows firm profits and, as we might have conjectured from the markup equations, profits decrease as the elasticity of substitution increases. But as in the case in consumer-welfare diagram, this effect largely disappears after a value of $\sigma=3$. There is very little effect of willingness to pay on firm profits.

Figure 5 plots total welfare, the sum of consumer welfare (factor income) and profits (N.B., the vertical axes of Figures $8 \mathrm{~A}$ and $8 \mathrm{~B}$ are indices, therefore they cannot be added together to get the vertical axis in Figure 8C). Total welfare is very insensitive the the elasticity of substitution. The conclusion is that increasing the substitutability of products is largely a distributional issue between consumer welfare and firm profits. This could change in a model with free entry as we shall note below.

Figures 9ABC show the case where standards improve complementarity as in Figure 7AB. One axis maps the ratio $X^{0} / X^{1}$ as shown in Figure 7A. Lower values of this ratio correspond a more "bowed-in" isoquant and thus to lower values of $\sigma$. The other axis is willingness to pay $(A)$ or inverse cost. It does not seem sensible for this ratio to be "very small", 
since this implies an increased willingness to pay even for one good alone, and it is not clear why this should be the case. Thus we run this parameter over a more limited range in this simulation. Results in Figure 9A show that consumer welfare increases with a fall in $X^{0} / X^{1}$ and an increase in willingness to pay. The interesting result in for profits in Figure 9B, in which we see that profits also improve with lower values of $X^{0} / X^{1}$. This is due to the fact that these lower values correspond to lower elasticities of substitution between types, and thus allow higher equilibrium markups. Figure 9C plots total welfare and not surprisingly this increases with decreases in $X^{0} / X^{1}$ and increases in willingness to pay. When standards make goods better complements, we conclude that consumer and producer interests may coincide.

It is often the case that in models with imperfect competition, results will depend greatly on whether or not there is free entry and exit of firms. Recognizing this, we added scale economies in the form of fixed costs to the $X$ sector, and allowed free entry and exit of firms to occur until profits are zero in the $X$ sector. We will not go into detail here, but merely report the differences this makes. In the case of increased substitutability, free entry and exit increases the change in welfare due to an increase in the elasticity of substitution from 0.5 to 10.0 by about $400 \%$. The lower markups due to the increased elasticity cause about $40 \%$ of firms to exit, and this leads to an efficiency gain of higher output per firm that outweighs a mitigating effect of exit on markups. Referring back to Figure $8 \mathrm{C}$, we must point out the the absolute effect is small, the $400 \%$ being an increase of $4 \%$ instead of $1 \%$.

In the case of increased complementarity, free entry and exit reduces the change in welfare due to a decrease in $X^{0} / X^{1}$ (decrease in s). The $20 \%$ decrease in $X^{0} / X^{1}$ in our simulations results in a welfare gain that is about $96 \%$ as large in the case of free entry and exit as it is in case 
of a fixed number of firms. This is due to entry of additional firms induced by the lower elasticity of substitutions. While this difference between free entry and no entry looks small compared to the case of increased substitutability, the absolute changes are larger in the complementarity case (consistent with Figures 9ABC), the $96 \%$ being an increase of about $10.9 \%$ versus $11.3 \%$. In summary then, the assumption of free entry and exit magnifies the favorable effects of increased substitutability, and reduces the effects in the case of increase complementarity. 


\section{6. $\quad$ Standards and international arbitrage}

Standards have consequences for the demand and the costs of trading products and services. In particular, standards can effect the scope for international arbitrage, which has implications for international consumption distortions, entry of new products and the efficiency of production in imperfectly competitive markets.

Different national standards can effect the costs of arbitrage in different ways. More specifically, differences can raise the variable or the fixed cost of arbitrage. The cost can apply to all trade with the commodity or only to arbitrage activities. The exact cost structure depends on border controls, test procedures and the need to adapt foreign varieties to the local market. Moreover, the effect on individual arbitrage by consumers and commercial arbitrage by parallel traders is potentially different. For sufficiently high costs, however, arbitrage is completely blocked irrespective of the type of arbitrage we are considering.

Throughout this section we focus on the arbitrage costs of different standards. In contrast to the previous sections, this section analyzes models in which the costs of different standards do not apply to the manufacturing firms production and distribution of the goods.

Before we study the effects of different standards it should be noted that arbitrage in international markets can be modeled in at least three ways, all of which are applied in the following analysis. One alternative is to derive an equilibrium condition for prices and impose this constraint on the solution. Under this assumption, arbitrage determines the equilibrium but does not occur in equilibrium. To the extent that arbitrage is a costly activity, this approach does not fully take into account the costs associated with price convergence. Another alternative is, therefore, to model arbitrage as an explicit activity. Arbitrage firms or parallel importers buy the 
goods in markets with low prices and ship them to markets with high prices. Under the assumption of free entry in the arbitrage sector, international price differentials will be bounded by the average cost of arbitrage. A final alternative is to focus on two extreme cases with fully integrated and perfectly segmented markets. The former case corresponding to a common standard in all markets and the latter case representing an equilibrium with different national standards. This is a particularly convenient way to model different national standards as a prohibitive cost for arbitrage.

In some cases commercial arbitrage is explicitly prohibited. For instance, parallel importers are generally not allowed to exploit international price differentials for patented, copyrighted or trade marked products between developing countries and the European Union. In other cases, individual arbitrage is prohibitively costly due to increasing returns to scale in the transportation technology, which makes it reasonable to focus on parallel trade.

The modeling approach should, therefore, be determined by the type of arbitrage and the costs associated with different arbitrage activities.

(i) Standards and international consumption distortions

First, we focus on the interaction between standards and "individual arbitrage", which refers to consumers buying the goods directly from a foreign market.

We have previously noted that standards can raise the fixed as well as the variable cost of arbitrage. There is no reason to rule out either of the barriers to arbitrage a priori. In many cases standards can be thought of as a mix of fixed and variable arbitrage costs of importing a good to a market with a different local standard. Testing procedures and border controls are mainly fixed 
costs. Increasing returns to scale in the transportation technology adds to this cost structure. Adapting the product to the local market may result in variable as well as fixed arbitrage costs. Both variable and fixed arbitrage costs of different standards can be incorporated in a derived individual arbitrage condition.

Consider a model with two goods $X$ and $Y$, and two countries $H$ and $F$. The price of $Y$ is normalized to 1 . The price of $X$ is $p_{H}$ in country $H$ and $p_{F}$ in country $F$. A representative consumer in market $H$ has a utility function $U(X, Y)$ and income $I$. Good $X$ has different standards in country $H$ and $F$ and importing $X$ from country $F$ to country $H$ is associated with a variable arbitrage cost $t$ and a fixed arbitrage cost $T$.

The arbitrage condition for country $H$ can be stated in the following way: the utility of buying the local standard of $X$ at local prices must be at least as high as the utility of buying the foreign standard at foreign prices, including all arbitrage costs associated with the different standard. More formally, the individual arbitrage condition for good $X$ in country $H$ is

$$
v\left(p_{H}, I\right) \geq v\left(p_{F}+t, I-T\right)
$$

where $v(p, I)$ is the indirect utility function for the representative consumer in market $H$. For instance, consider a CES utility function

$$
U(X, Y)=\left(X^{b}+Y^{b}\right)^{1 / b}, \sigma \equiv 1 /(1-b) .
$$

Maximizing utility with respect to income gives the indirect utility function 


$$
v(p, I)=I\left[\frac{\left(1+p^{\sigma-1}\right)^{\frac{1}{\sigma-1}}}{p}\right] .
$$

We can now proceed to study the effects of fixed and variable costs associated with different nationals standards. Evaluating (20) at the fixed cost $T$ gives the arbitrage condition for country $H$ at pure fixed costs.

Figure 10 illustrates the arbitrage condition graphically. The domestic consumption bundle is A at price $p_{H}$ and income $I$ in country $H$. For some fixed cost $T$ and price $p_{F}$ in country $F$ a representative consumer in country $H$ is indifferent between $\mathrm{A}$ and buying the goods in $F$ at the foreign consumption bundle A'. It follows that condition (20) is satisfied for any price at least as high as $p_{F}$ in country $F$. Moreover, arbitrage may be unprofitable despite a very high price in the domestic market. At price $p_{F}$ in country $F$ and a fixed cost higher than $T_{\text {lim }}$ arbitrage is not profitable for consumers in market $H$ at any price in the domestic market.

Next, evaluating (20) at the variable cost $t$ is straightforward. It implies that the conventional arbitrage condition $p_{H} \leq p_{F}+t$ must hold. The consumer is indifferent between $p_{H}$ and $p_{F}$ at income $I$, if and only if the variable transportation cost results in an optimal choice at A both at domestic and foreign prices.

The previous results can be used to study the welfare effects of a consumption distortion caused by different national standards in an international monopoly. If arbitrage is permitted, it imposes a restriction on the international price differential but no arbitrage will actually occur in equilibrium. Sector $Y$ is assumed to be perfectly competitive with marginal cost equal to one. $X$ is produced at marginal cost $m c_{j}$ in market $j=H, F . X_{j}\left(p_{j}\right)$ is the consumption of $X$ in market $j$. 
There is a single manufacturing firm in sector $X$, which is selling the product in market $F$ and $H$. The cost of different standards apply to individual arbitrage only and the manufacturing firm can distribute two different standards of $X$ without additional costs. Since trade is costless for the manufacturing firm and the marginal cost is fixed, production can be located in country $H$ or $F$ without any implications for the equilibrium. The monopolist in sector $X$ sets prices $p_{H}$ and $p_{F}$ to maximize

$$
\sum_{j=H, F} X_{j}\left(p_{j}\right)\left(p_{j}-m c\right)
$$

subject to $(20)$.

Figures $11 \mathrm{~A}-\mathrm{D}$ present the simulation of this partial-equilibrium model with fixed and variable arbitrage costs of different national standards. It is assumed that the elasticity of substitution is $\sigma_{H}=2$ in market $H$ and $\sigma_{F}=3$ in market $F$ and the marginal cost is equal in both markets, i.e. $m c_{H}=m c_{F}=0.50$.

In the perfectly segmented equilibrium with prohibitively costly arbitrage the monopolist would set prices $p_{H}=1.366$ and $p_{F}=1$. Figure 11A plots the price differential $p_{H}-p_{F}$ for different variable and fixed arbitrage costs when individual arbitrage is permitted. For $T=0$, the price differential increases linearly in the variable arbitrage cost to $t=0.366$, where arbitrage is unprofitable at segmented prices. A fixed arbitrage cost $T$, on the other hand, makes arbitrage unprofitable at rather low values. For any $T>0.14$, segmented prices satisfy the individual arbitrage condition. A rather small fixed arbitrage cost of different national standards could, therefore, support the assumption of segmented international markets. Figure 11B illustrates the 
welfare effects. Total welfare is calculated as a welfare index, which is set to 100 in the segmented equilibrium. The simulation shows that total welfare including monopoly profits is some 2 percent higher in the integrated equilibrium than in a segmented equilibrium with prohibitively costly different national standards. The main reason for the increase in total welfare is that equalized prices in country $H$ and $F$ results in a reduction of the international consumption distortion caused by different local prices in the segmented equilibrium. However, it is also interesting to note that the benefits are asymmetrically distributed in country $H$ and $F$. Figure 11C-D show the difference in consumer welfare in country $F$ and country $H$. Despite a moderate increase in total welfare, we see a sharp decline in consumer welfare in country $F$, i.e. the lowprice country, as the arbitrage costs of different national standards are reduced. Figure 11D shows that consumer welfare in country $F$ falls approximately 6 percent as the arbitrage cost of different standards are reduced. Correspondingly, the consumer welfare in country $H$ increases more than 9 percent as illustrated in Figure 11C. Reducing the arbitrage cost of different standards reduces the consumption distortion caused by different prices and result in higher total welfare, but the winners are the consumers in high-price countries while consumers in low-price countries and entrepreneurs are losing.

The welfare effects in low-price countries can, however, be quite different when the cost of the different standards apply not only to the arbitrage activity but also to the output decision of the monopolist. If different national standards raise the real production and distribution cost for the manufacturing firm, it can change the optimal output for the manufacturing firm. One important difference between a fixed and variable trade cost of different national standards is that the latter (but not the former) change the marginal incentives of the monopolist. This effect can 
be studied in our model.

Let the variable cost of different standards apply to both arbitrage and output by the monopolist. We consider first production of good X in country F, with exports to country $\mathrm{H}$. Then we consider production of good $\mathrm{X}$ in country $\mathrm{H}$, with exports to country $\mathrm{F}$. It is assumed that the arbitrage cost and the real trade cost of different standards is the same for individual consumers and the manufacturing firm. The marginal cost in market $j$ is $t+m c_{j}$ when the monopolist is exporting the product to market $j$ (assuming a symmetric cost from $H$ to $F$ and $F$ to $H$ ). It is assumed that the individual arbitrage condition holds in equilibrium. In other words, arbitrage is a constraint on the international price differential in sector $\mathrm{X}$, but no arbitrage occurs in equilibrium.

Figures $12 \mathrm{~A}$ - D illustrate the simulations. Figure 12A shows the prices in market $H$ and $F$ when the monopolist is exporting from the market $F$ to $H$. If the variable trade cost increases, the higher marginal cost in market $H$ results in a higher optimal price in this market. The higher price in market $H$ results in a higher (not lower) price in market $F$ due to the arbitrage activity for low variable costs. For very high variable costs the revenues in market $H$ is a small share of the total profit of the monopolist and the arbitrage condition has less impact on the price in market $F$, and eventually the price in market $F$ is falling. Welfare in market $F$ has a u-shaped form as illustrated in Figure 12C. Consumers in market $F$ prefer no difference in national standards, i.e. no variable $\operatorname{cost}(t=0)$, to standards that result in a moderate variable cost. For consumers in market $H$ the integrated equilibrium (with $t=0$ ) dominates any other equilibrium for consumers in market $H$. Next, Figure 12B shows the prices in market $H$ and $F$ when the monopolist is exporting from market $H$ to $F$. A higher marginal cost in market $F$ (including the trade cost) results in a higher 
optimal price in market $F$. For low variable costs the arbitrage condition binds but the effect on the price in market $H$ is less strong. For high variable costs the arbitrage condition is not binding. For very high variable costs the price in market $F$ is even higher than the price in market $H$. Again consumers in market $H$ prefer the integrated equilibrium. Moreover, figure $12 \mathrm{~d}$ shows that consumers in market $F$ prefer the integrated equilibrium to any difference in national standards.

(ii) Standards and parallel trade

One important alternative to individual arbitrage is commercial arbitrage, i.e. arbitrage undertaken by firms. Commercial arbitrage in products protected by intellectual property rights trademarks, patents and copyrights - is often referred to as "parallel imports" or "gray market imports" when the trade occurs without the intellectual property right holder's consent. Although, commercial arbitrage is a wider term than parallel imports we will use the terms synonymously in the subsequent analysis.

The most important reason for commercial arbitrage as an alternative to individual arbitrage is increasing returns to scale in the trade activity. A fixed cost of different national standards can make individual arbitrage prohibitively costly, but still feasible for commercial arbitrage firms.

We extend the partial-equilibrium model from the previous subsection to allow for commercial arbitrage. The model still has two goods $X$ and $Y$, and two countries $H$ and $F$. The price of $X$ is $p_{H}$ in country $H$ and $p_{F}$ in country $F$. It is assumed that $H$ is the high-price country and $F$ is the low-price country in equilibrium. The costs of different standards apply to arbitrage activities but do not apply to the production and distribution by the manufacturing firm. A 
monopolist produces $X$ for markets $H$ and $F$ at marginal cost $m c_{j}$ in market $j=H, F$. Without loss of generality it is assumed that production is located in $\mathrm{H}$. The monopolist chooses outputs for market $H$ and $F$. Then $n$ arbitrage firms non-cooperatively choose to ship a quantity $x^{a}$ from the high-price market to the low-price market. In its shipment decision each arbitrage firm takes the other arbitrage firms' quantities as given.

The commercial arbitrage condition for country $H$ can be stated in the following way: the price differential between market $H$ and market $F$ must be less than or equal to the average cost for an arbitrage firm to import the product from market F. More explicitly, the commercial arbitrage condition for good $X$ in country $H$ is

$$
\left|p_{H}-p_{F}\right| \leq \frac{T}{x^{a}}+t
$$

where $x^{a}$ is the quantity shipped from market $F$ to market $H$ by the arbitrage firm. $T$ is the fixed arbitrage cost and $t$ is the variable arbitrage cost. In other words, condition (24) is a free entry condition for the arbitrage activity. Arbitrage firms enter until there is no excess profit in equilibrium.

In the following analysis we focus on a pure fixed arbitrage cost of different national standards and no variable arbitrage cost, i.e. $t=0$. Assuming that all arbitrage firms are identical the total arbitrage quantity is

$$
X^{a}=\frac{\left(p_{H}-p_{F}\right) n}{-d p_{H} / d X-d p_{F} / d X}
$$


subject to $X_{j}\left(p_{j}\right)-X_{j}^{a}\left(p_{H}, p_{F}\right) \geq 0$, which follows from the $n$ first order conditions of the arbitrage firms. Let the exported quantity from $F$ be denoted $X_{F}^{a}=-X^{a}$ and the identical imported quantity in $\mathrm{H}$ be denoted $X_{H}^{a}=X^{a}$. The monopolist in sector $\mathrm{X}$ set prices $p_{H}$ and $p_{F}$ to maximize

$$
\sum_{j=H, F}\left(X_{j}\left(p_{j}\right)-X_{j}^{a}\left(p_{H}, p_{F}\right)\right)\left(p_{j}-m c\right)
$$

Figure $13 \mathrm{~A}-\mathrm{C}$ shows the results of the simulation of this partial-equilibrium model. It is assumed that the elasticity of substitution is $\sigma_{H}=2$ in market $H$ and $\sigma_{F}=3$ in market $F$ and the marginal cost is equal in both markets, i.e. $m c_{H}=m c_{F}=0.50$. Both markets have a large but identical number of consumers. The fixed arbitrage cost $T$ is redefined to be in per-capita terms for the arbitrage firms, i.e. $T=T F / S$, where $T F$ is the fixed arbitrage cost of the standard and $S$ is the number of consumers. $T F$ is prohibitive to an individual consumer. The variable arbitrage cost is zero $(t=0)$.

The optimal prices in the segmented equilibrium without arbitrage is $p_{H}=1.366$ and $p_{F}=1$. Figure 13A shows how prices in market $F$ and $H$ changes when more arbitrage firms enter the market. The price in market $H$ falls sharply when the first arbitrage firm enters the market. Correspondingly, the price in market $F$ is raised as soon as arbitrage firms start to enter. The price in both markets converges to $p_{H}=p_{F}=1.117$ as the number of arbitrage firms goes to infinity. This correspond to the integrated equilibrium price with costless individual arbitrage.

Figure 13B illustrates how the price differential between market $H$ and $F$ depends on the 
fixed arbitrage cost of the standard. The fixed arbitrage cost determines the number of arbitrage firms. For a high fixed arbitrage cost, less arbitrage firms find it profitable to enter.

Consequently, the price differential between market $H$ and $F$ increases in the fixed arbitrage cost of the standard. The profit of the monopolist is increasing in the fixed arbitrage cost of the standard.

The total welfare effects depend on the size of the fixed arbitrage cost. Figure 13C illustrates the total welfare index (set to 100 in the segmented equilibrium). The total welfare (including monopoly profits) is approximately 2 percent higher in the integrated equilibrium. Total welfare falls as the fixed cost increases. The main reason is a larger price differential between market $H$ and $F$, which results in an international consumption distortion identical to the distortion in the previous section (6.i).

(iii) Standards and marketing of new products

Different national standards can be used to facilitate the introduction of products in markets with large variation in preferences or income. More specifically, different local standards may be used to promote investment in marketing and (partial) entry of products in low-income markets. A monopolist may find it profitable to introduce a new product in a low-income country as long as the supply in this market does not spill-over to a high-income market but unprofitable if he is forced to charge the same price to consumers in both high- and low-income markets. Under such conditions different national standards can be used to prevent arbitrage and facilitate marketing of new products in low-income or low-valuation markets.

The interaction between arbitrage and entry can be modeled as a discrete choice to enter a 
market or stay out. It can alternatively be modeled as a problem of partial entry, e.g. investment in marketing. We modify our international monopoly model along the lines of this latter modeling approach. The monopolist incurs a cost $c\left(\theta_{j}\right)$ to inform a fraction $\theta_{j}$ of the consumers in market $j$ about product $X$, where $c^{\prime}\left(\theta_{j}\right)>0, c^{\prime \prime}\left(\theta_{j}\right)<0$. The resulting demand for product $\mathrm{X}$

$$
D_{j}\left(\theta_{j}, p_{j}\right)=\theta_{j} X_{j}\left(p_{j}\right)
$$

and the monopolist maximizes

$$
\sum_{j=H, F} D_{j}\left(p_{j}\right)\left(p_{j}-m c\right)-c\left(\theta_{j}\right)
$$

In the segmented equilibrium, prices are independent of the level of information in market $H$ and $F$. The first order conditions with respect to $\theta_{j}$ is

$$
\pi_{j}\left(p_{j}^{*}\right)-c^{\prime}\left(\theta_{j}\right)=0
$$

where $\pi_{j}\left(p_{j}^{*}\right)$ is the per capita revenue in market $j$ from informed consumers. Segmented prices maximizes $\pi_{j}\left(p_{j}^{*}\right)$ and (29) implies that information is maximized at these prices. A direct consequence of this result is that arbitrage, i.e. a reduced price differential, reduces the information in both markets. In other words, different national standards and market segmentation can promote entry and investment across different markets.

Figures 14A - B illustrate the results of the simulations for this model. We have simplified 
the demand in market $j$ to be $D_{j}\left(\theta_{j}, p_{j}\right)=\theta_{j}\left(a_{j}-p_{j}\right)$, where $a_{H}=3, a_{F}=2$. In the segmented equilibrium without arbitrage the optimal prices are $p_{H}=1.5$ and $p_{F}=1$. For any variable arbitrage cost $t>0.5$ segmented prices are robust to arbitrage. The optimal levels of information in the segmented equilibrium are $\theta_{H}=0.562, \theta_{F}=0.25$. The effect of arbitrage on the information in market $H$ and market $F$ is illustrated in Figure 14A. Compared to the segmented equilibrium the information in market $F$ is some 13 percent lower in the equilibrium without different national standards (i.e. $t=0)$. Correspondingly, the information in market $H$ is approximately 1 percent lower. In other words, the monopolist finds it less profitable to invest in marketing in the lowprice country when it is forced to charge the same price in both markets. Figure 14B shows the effect on total welfare. We compare the total welfare when the information in both markets is fixed to the segmented level with the welfare at endogenous information levels. Total welfare including monopoly profits is measured as an index which is equal to 100 in the segmented equilibrium. The result shows that the negative effect of less provision of information at very low variable costs dominates the positive effect of the reduced international price differential. Welfare in the integrated equilibrium is 0.3 percent lower compared to the perfectly segmented equilibrium. Welfare is approximately 0.7 percent higher at intermediate variable arbitrage costs, due to a relatively small negative effect on information but moderate positive effect on the price differential.

(iv) Standards and production efficiency under increasing returns to scale

So far we have considered optimal pricing by a monopoly (similar results hold for any fixed number of manufacturing firms) and we have concluded that different national standards 
can result in international consumption distortions but also enhance entry of products in lowincome markets. Another important effect of standards, however, is the effect on production efficiency and the number of firms active in equilibrium. We have previously illustrated that a reduced arbitrage cost of different standard may lead to a reduced international price differential in imperfectly competitive industries. Consequently, market integration may reduce the profits of firms, which potentially can lead to exit and more efficient production. This effect can be illustrated in a very simple model.

Consider again a model with two goods $X$ and $Y$, and two countries $H$ and $F$. The $X$ sector is imperfectly competitive but entry and exit is free, $n$ firms incur a fixed cost $C$ and noncooperatively choose quantities for market $F$ and $H$. The marginal cost of production is assumed to be $m c$ in both markets and for all firms. There are no trade costs and the costs of different standards do not apply to manufacturing firms.

First, it is assumed that different national standards makes arbitrage prohibitively costly and result in perfectly segmented markets and the first order condition for firm $i$ in the $X$ sector is

$$
\frac{d p_{j}\left(X_{j}\right)}{d x_{j i}} x_{j i}-\left(p_{j}\left(X_{j}\right)-m c\right)=0
$$

for market $j=F, H$, where $x_{j i}$ is the quantity chosen by firm $i$ in market $j$. The number of firms is determined by the free entry condition

$$
\sum_{j=H, F}\left(p_{j}\left(n x_{j}^{*}\right)-m c\right) x_{j}^{*}-C \leq 0
$$


where $n$ is the complementary variable and $x_{j}^{*}$ the non-cooperative equilibrium quantity with $n$ firms.

With a common standards in all markets it is assumed that markets are perfectly integrated and the first order condition for firm $i$ in sector $X$ is reduced to

$$
\frac{d p(X)}{d x_{i}} x_{i}-(p(X)-m c)=0
$$

where $p(X)$ is the inverse demand function for the integrated market and $x_{i}$ is the quantity chosen by firm $i$ for the integrated market. The number of firms is determined by the free entry condition

$$
\left(p\left(n x^{*}\right)-m c\right) x^{*}-C \leq 0
$$

where $n$ is the complementary variable.

Figures 15A-D report the results of the simulations of this model. We have simplified the demand in market $j$ to be $D_{j}\left(p_{j}\right)=\left(a_{j}-p_{j}\right)$, where $a_{H}=3, a_{F}=2$. The fixed cost of manufacturing ranges from 0.0 to 1.0 . In the equilibrium with a fixed cost equal to 0 the price is defined to be equal to the marginal cost, i.e. $p=m c$. Figure $15 \mathrm{~A}$ illustrates equilibrium prices. Prices are increasing in the fixed cost of production as less and less firms find it profitable to enter the market. In the segmented equilibrium, prices (PRICEHS and PRICEFS) are more and more dispersed as the fixed cost increases. A smaller number of firms gives each remaining firm more market power and the scope for price differentiation increases. The integrated price (PRICEHI) is lower than the segmented price in market $H$ but higher than the segmented price in 
market $F$. We have also computed the integrated equilibrium price for the same number of firms as in the segmented equilibrium (PRICEC). This price is lower than the integrated price as more firms are active in equilibrium, but the difference is very small.

Figure 15B shows the effect on total welfare. Welfare is measured as an index set to 100 for the segmented equilibrium at every level of the fixed cost, i.e. it is reindex to 100 in the segmented equilibrium for every $C$. The total welfare in the integrated equilibrium is higher than the total welfare in the segmented equilibrium for any given fixed cost. The difference between total welfare in the segmented and integrated equilibrium is increasing in the fixed cost (WELF_T). Total welfare is almost 5 percent higher in the integrated equilibrium than in the segmented equilibrium when the fixed cost is close to one. The total welfare difference between the integrated and segmented equilibrium is the sum of the reduced international consumption distortion and more efficient production when some firms exit the market. The positive effect of the reduced international consumption distortion is measured as the increase in welfare in an integrated equilibrium without exit (WELF_P). Approximately $2 / 3$ of the welfare gain can be attributed to a reduced international consumption distortion and 1/3 to more efficient production.

Figures $15 \mathrm{C}$ and $\mathrm{D}$ show that the benefits from market integration is not distributed equally. Consumers in market $F$ are better off in the segmented equilibrium and consumers in market $H$ are better off in the integrated equilibrium. 


\section{Summary}

The purpose of this paper is to consider approaches to formally modeling standards and technical regulations governing trade. A criterion for the analysis is that they be potentially implementable in applied general-equilibrium models with real data.

The simplest approach to standards is that, when they differ between countries, they constitute a real trade cost for exports trying to penetrate the foreign market. Our results in this case indicate that incompatible standards are particularly harmful for small/poor countries who cannot win a "standards war".

Obviously, this situation is often too simple, and in particular standards can prove beneficial to exporters by certifying their products as safe, healthy, compatible with local complementary goods (e.g., the electrical supply) and so forth. In section 3, we therefor add to our analysis by showing alternative ways to model increased willingness to pay be local consumers for imported products meeting the local standard. We suggest that this must be done with care, particularly because different methods of modeling willingness to pay will leave to different welfare effects.

Section 4 extends section 3 by noting that standards may be more a fixed cost than a variable cost such as a once-and-for-all redesign cost. If this cost is a quasi "public good" across firms, then there may be multiple equilibria. In one, firms export while in another, local firms do not export. We illustrate that the welfare differences between these two outcomes may be large, creating an important coordination role for public policy.

Section 5 notes how standards can alter the substitutability or complementarity between local and foreign products. As in section 3, we note that this has to be modeled carefully so as 
not to produce misleading welfare results. Our examples indicate that consumers and imperfectly- competitive firms will have opposing interests when standards increase substitutability, but have reinforcing interests when standards increase complementarity.

Section 6 analyzes how standards alter the ability of consumers and independent (from the manufacturer) firms to conduct arbitrage and parallel trade. We assume that the original manufacturer has no costs in meeting different standards (and indeed sometimes creates them precisely to defeat arbitrage) while other firms and consumers do. Plausible assumptions predict that the manufacturer may set a lower price in a foreign (e.g., developing) country than in its home country if it can segment the two markets via different standards. The ability of independent firms to arbitrage may increase total world welfare but may worsen the welfare in the developing country as the original manufacturer raises prices there to prevent arbitrage, or engages in less informative advertising.

In all sections, we develop simple numerical models to compute solutions, illustrating that our approaches are implementable. Significant obstacles to full implementation with real data remain, however, since the beneficial effects of standards, and indeed often the costs, are largely unobservable in published data. 
Table 1: Standard in country $\mathrm{h}$ imposes a fixed cost for entering the export market in country $f$ (creates multiple equilibria)

Country h

Country $f$

\begin{tabular}{|c|c|c|c|c|c|c|}
\hline & cons $h$ & profit $\mathrm{h}$ & welf $h$ & cons $f$ & profit $f$ & welf $\mathrm{f}$ \\
\hline $\begin{array}{l}\text { Benchmark } \\
\text { cost }=0 \\
\text { wtp }=1.0\end{array}$ & 1.000 & 1.000 & 1.000 & 1.000 & 1.000 & 1.000 \\
\hline $\begin{aligned} & \text { eq. } \text { with exports } \\
& \text { cost }= 0.1 \\
& \text { wtp }= 1.0 \\
& \text { eq. with no exports }\end{aligned}$ & $\begin{array}{l}0.989 \\
0.923\end{array}$ & $\begin{array}{l}1.060 \\
1.540\end{array}$ & 0.996 & $\begin{array}{l}0.987 \\
0.958\end{array}$ & $\begin{array}{l}0.843 \\
0.649\end{array}$ & $\begin{array}{l}0.973 \\
0.927\end{array}$ \\
\hline $\begin{aligned} \text { eq. } \text { with exports } \\
\begin{aligned} \operatorname{cost}= & 0.1 \\
\text { wtp }= & 1.10 \\
& \text { eq. with no exports }\end{aligned}\end{aligned}$ & 0.997 & 1.019 & 0.999 & $\begin{array}{l}1.001 \\
0.958\end{array}$ & 0.980 & $\begin{array}{l}0.999 \\
0.927\end{array}$ \\
\hline $\begin{aligned} \quad \text { eq. } \text { with exports } \\
\text { cost }=0.1 \\
\text { wtp }=1.25\end{aligned}$ & 1.008 & 0.977 & 1.005 & 1.023 & 1.260 & 1.041 \\
\hline eq. with no exports & 0.923 & 1.540 & 0.985 & 0.958 & 0.649 & 0.927 \\
\hline
\end{tabular}




\section{Table 2: Calibration for the models of sections 2-4.}

\begin{tabular}{|c|c|c|c|c|c|c|c|c|c|c|c|c|c|c|c|c|c|}
\hline & $\mathrm{YH}$ & YF & $\mathrm{XH}$ & $\mathrm{XHH}$ & $\mathrm{XHF}$ & $X F$ & XFF & XFH & WHC & WFC & WHE & WFE & $\mathrm{CONH}$ & CONF & ENTH & ENTF & $\begin{array}{r}\text { ROW } \\
\text { SUM }\end{array}$ \\
\hline $\mathrm{CY}$ & 200 & 50 & & & & & & & -180 & -45 & -20 & -5 & & & & & 0 \\
\hline $\mathrm{CXH}$ & & & 160 & -128 & -32 & & & & & & & & & & & & 0 \\
\hline $\mathrm{CXHH}$ & & & & 160 & & & & & -144 & & -16 & & & & & & 0 \\
\hline CXHF & & & & & 40 & & & & & -36 & & -4 & & & & & 0 \\
\hline CXF & & & & & & 40 & -8 & -32 & & & & & & & & & 0 \\
\hline CXFF & & & & & & & 10 & & & -9 & & -1 & & & & & 0 \\
\hline CXFH & & & & & & & & 40 & -36 & & -4 & & & & & & 0 \\
\hline UTILH & & & & & & & & & 360 & & 40 & & -360 & & -40 & & 0 \\
\hline UTILF & & & & & & & & & & 90 & & 10 & & -90 & & -10 & 0 \\
\hline $\mathrm{LH}$ & -160 & & -40 & & & & & & & & & & 200 & & & & 0 \\
\hline $\mathrm{KH}$ & -40 & & -120 & & & & & & & & & & 160 & & & & 0 \\
\hline LF & & -40 & & & & -10 & & & & & & & & 50 & & & 0 \\
\hline $\mathrm{KF}$ & & -10 & & & & -30 & & & & & & & & 40 & & & 0 \\
\hline $\mathrm{MKHH}$ & & & & -32 & & & & & & & & & & & 32 & & 0 \\
\hline MKHF & & & & & -8 & & & & & & & & & & 8 & & 0 \\
\hline MKFF & & & & & & & -2 & & & & & & & & & 2 & 0 \\
\hline MKFH & & & & & & & & -8 & & & & & & & & 8 & 0 \\
\hline $\begin{array}{l}\text { COLUMN } \\
\text { SUM }\end{array}$ & 0 & 0 & 0 & 0 & 0 & 0 & 0 & 0 & 0 & 0 & 0 & 0 & 0 & 0 & 0 & 0 & 0 \\
\hline
\end{tabular}

A column sum of zero indicates "zero profits" or more relevant here, product exhaustion (because entrepreneurs earn profits) for an acitivity. Revenues received from sales are exhausted in payments to factors and markup revenues

A row sum of zero indicates market clearing; e.g., supply equals demand for that good or factor, or that markup revenues are some agent's income. 


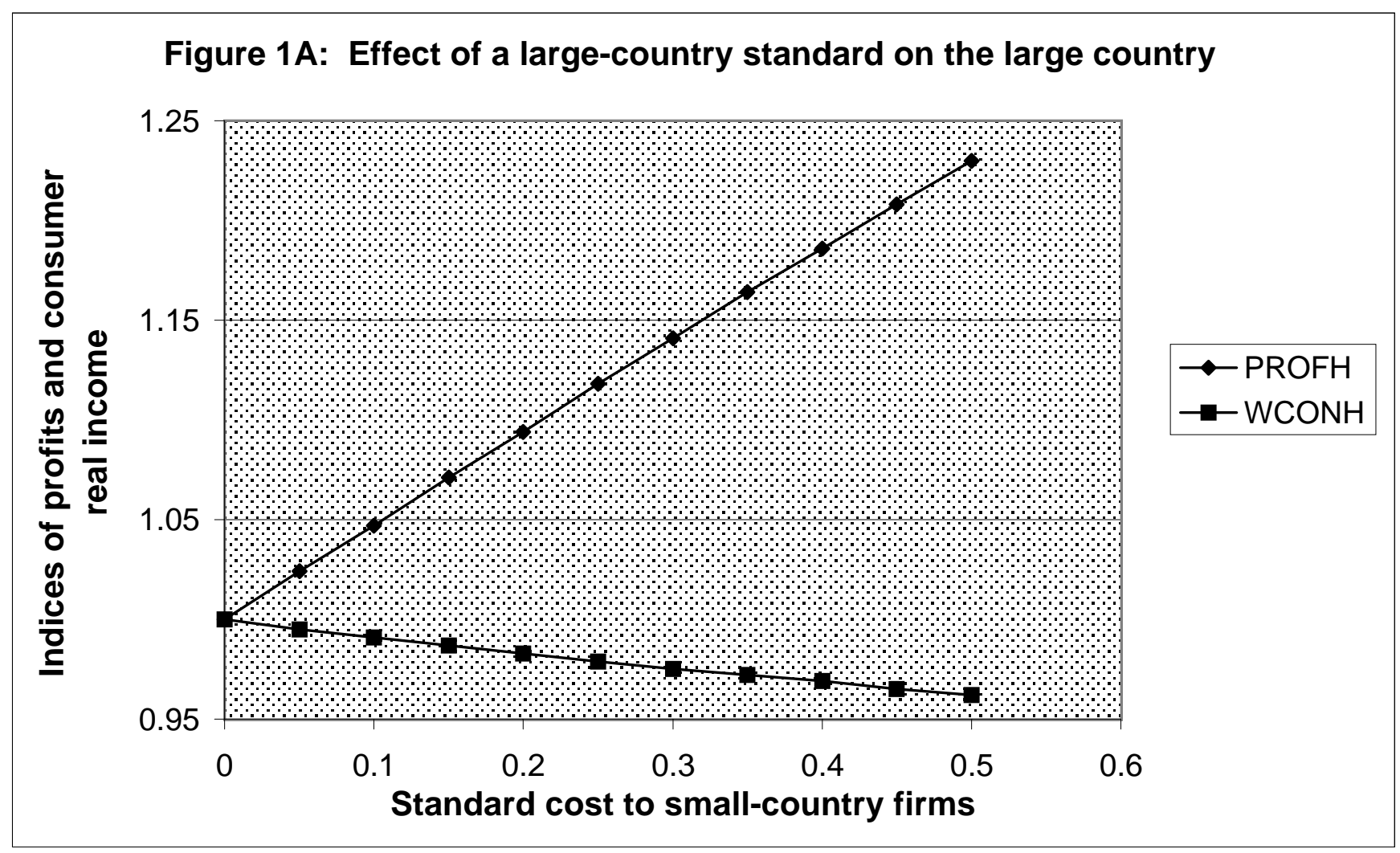

Figure 1B: Effect of a large-country standard on the small country

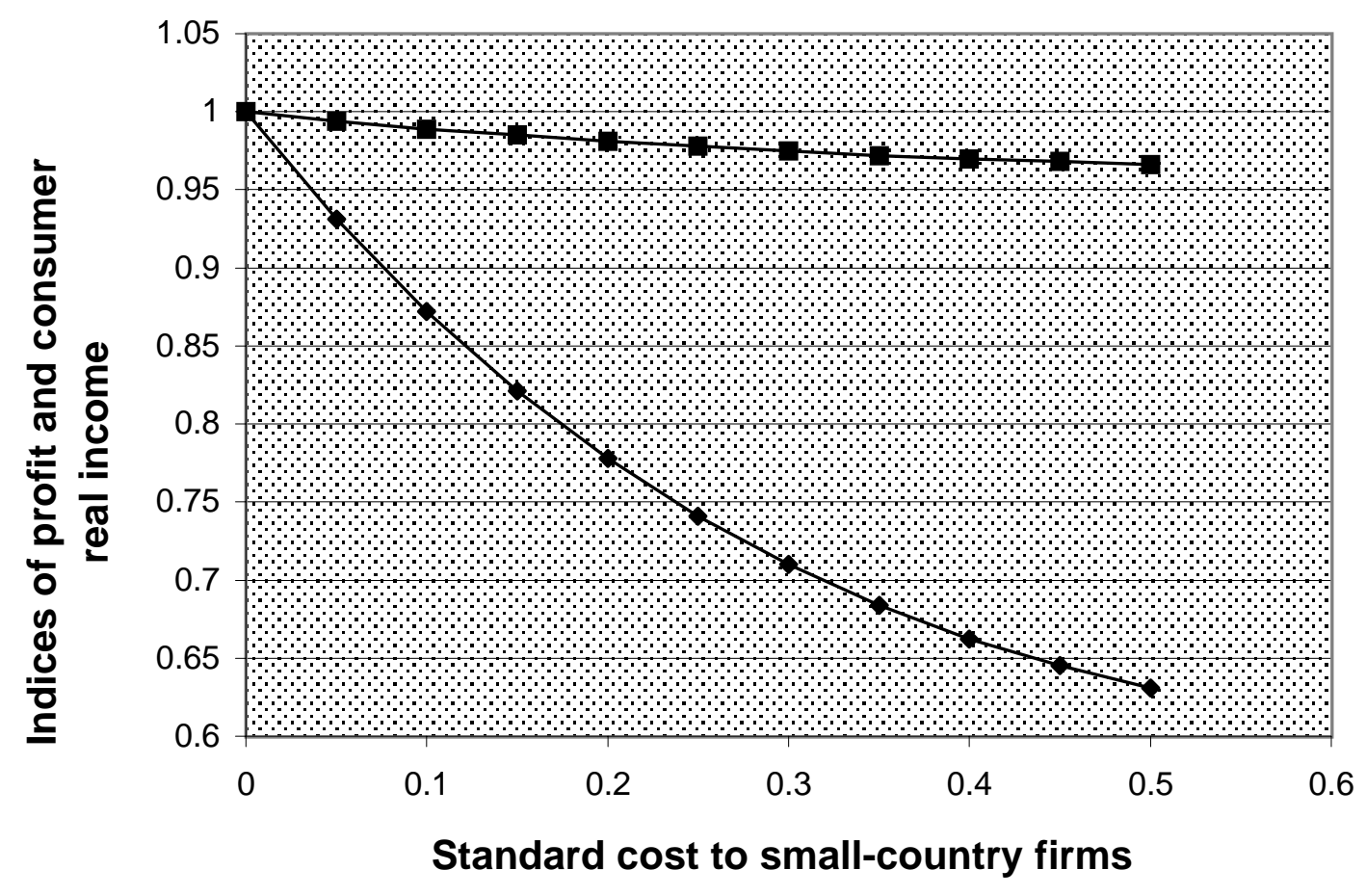

$\rightarrow-$ PROFF

$\rightarrow-$ WCONF 


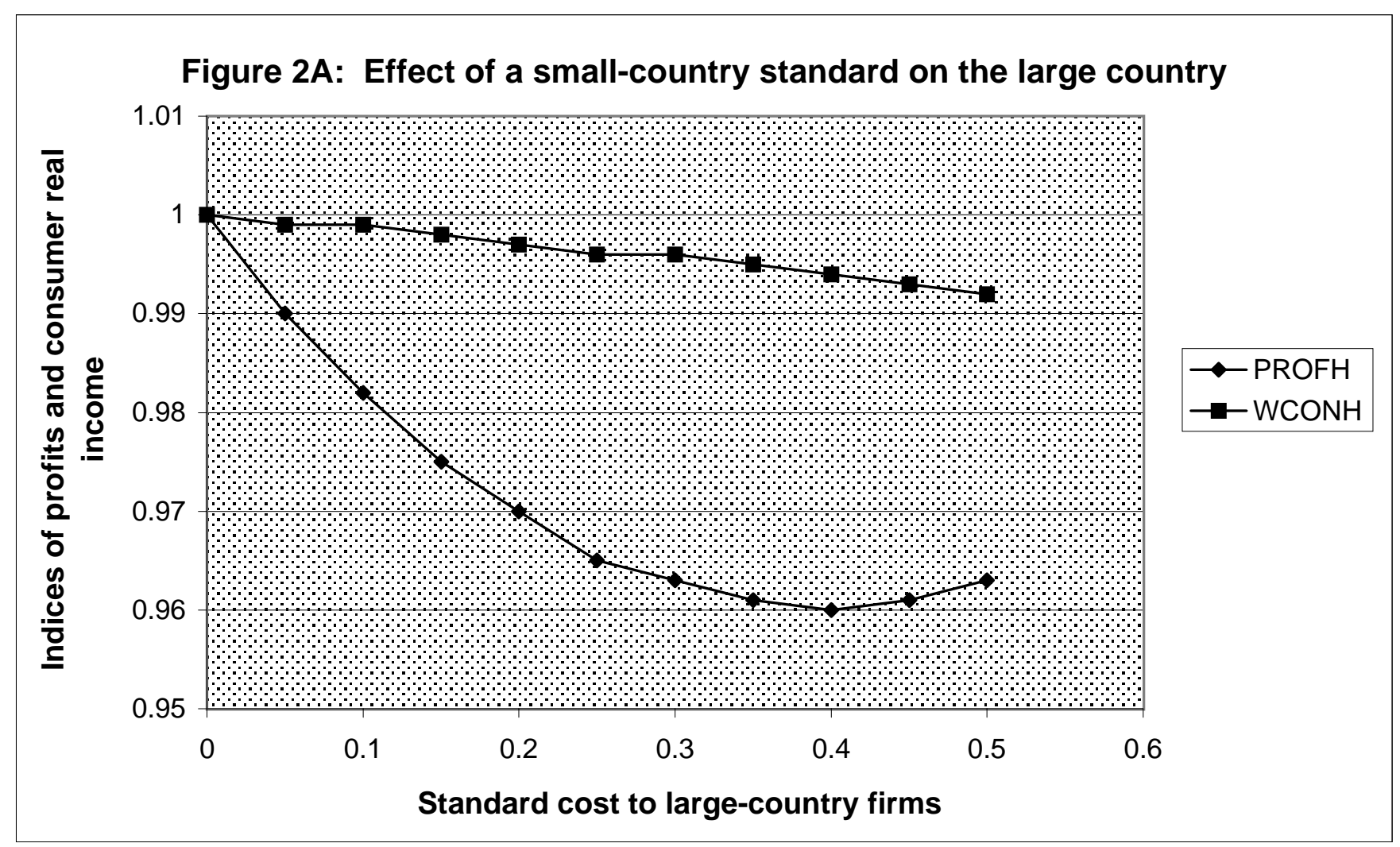

Figure 2B: Effect of a small-country standard on the small country
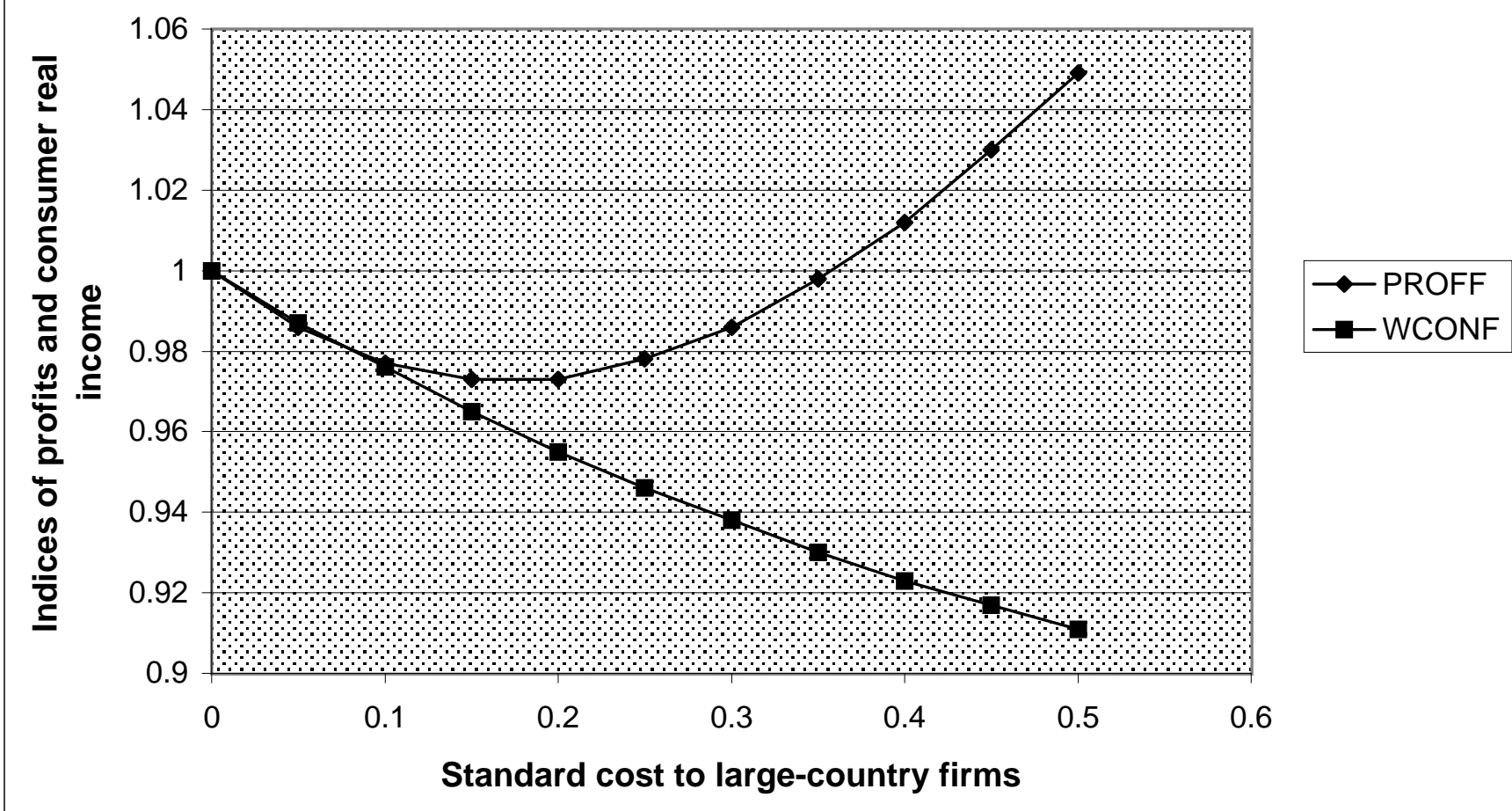

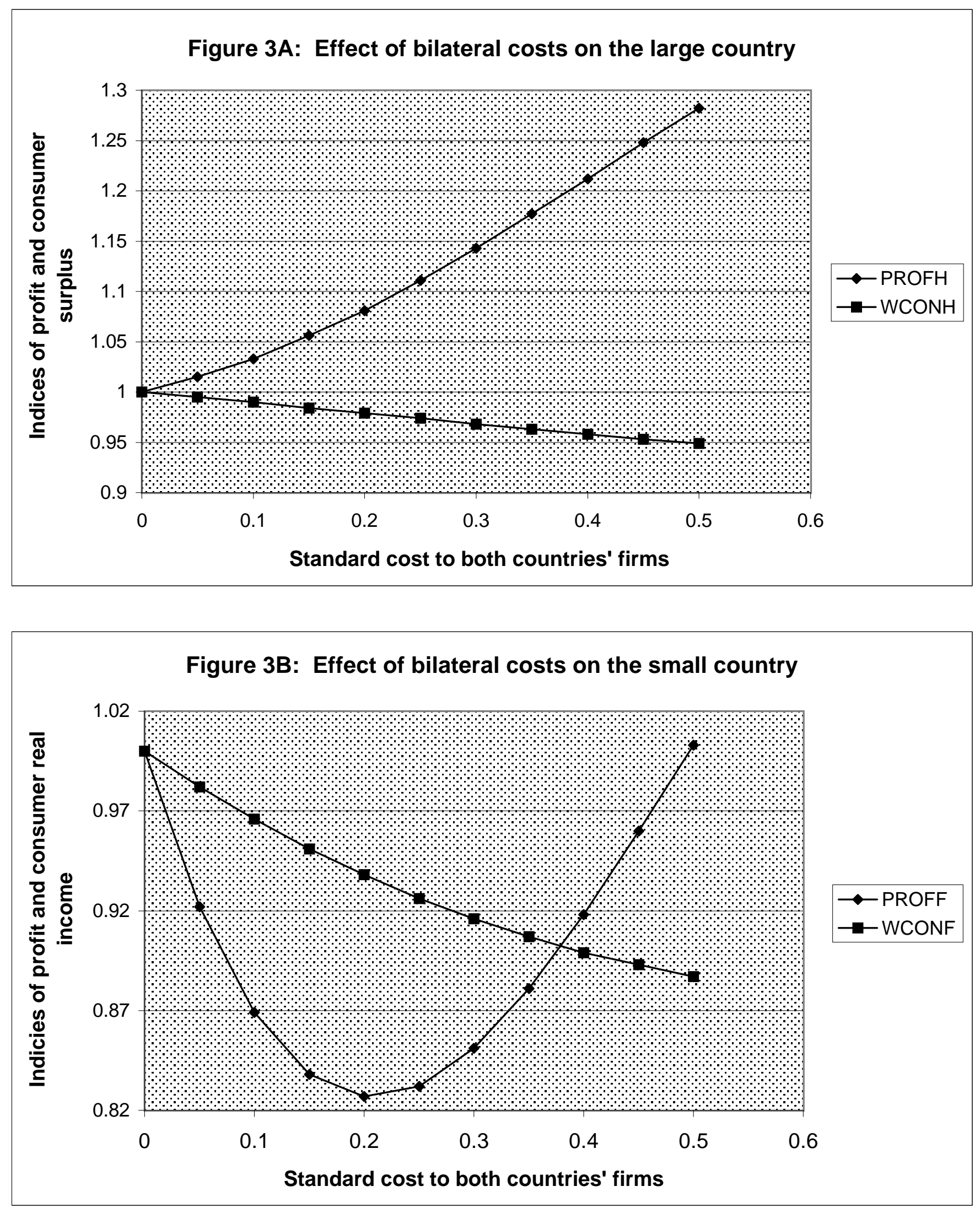
Figure 4A: Standard increases willingness to pay for $X_{f}$, version 1

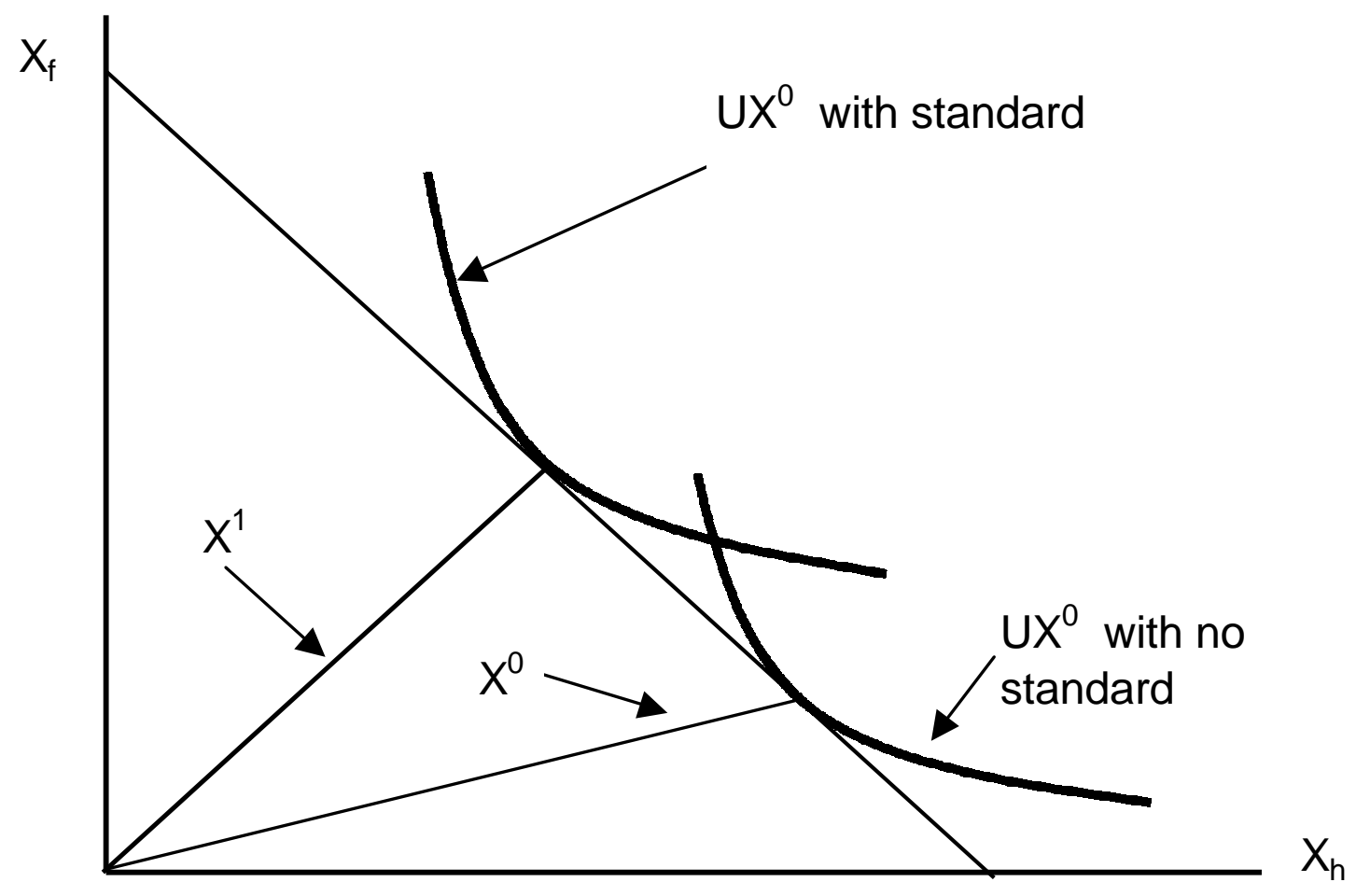

Figure 4B: Standard increases willingness to pay for $\mathrm{X}_{\mathrm{f}}$, version 2

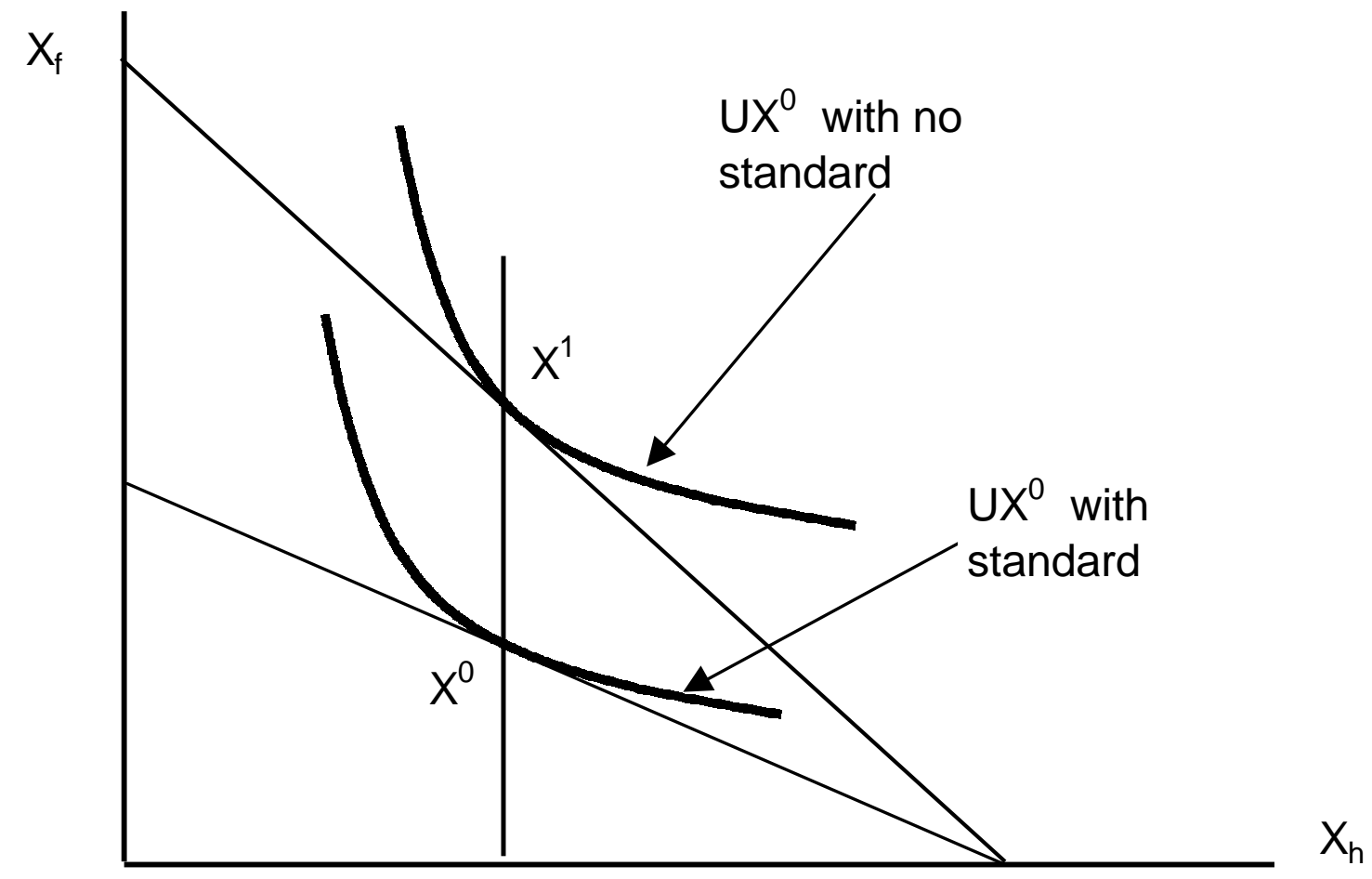


Figure 5A: Effect of a large-country standard on firm profits in the small country

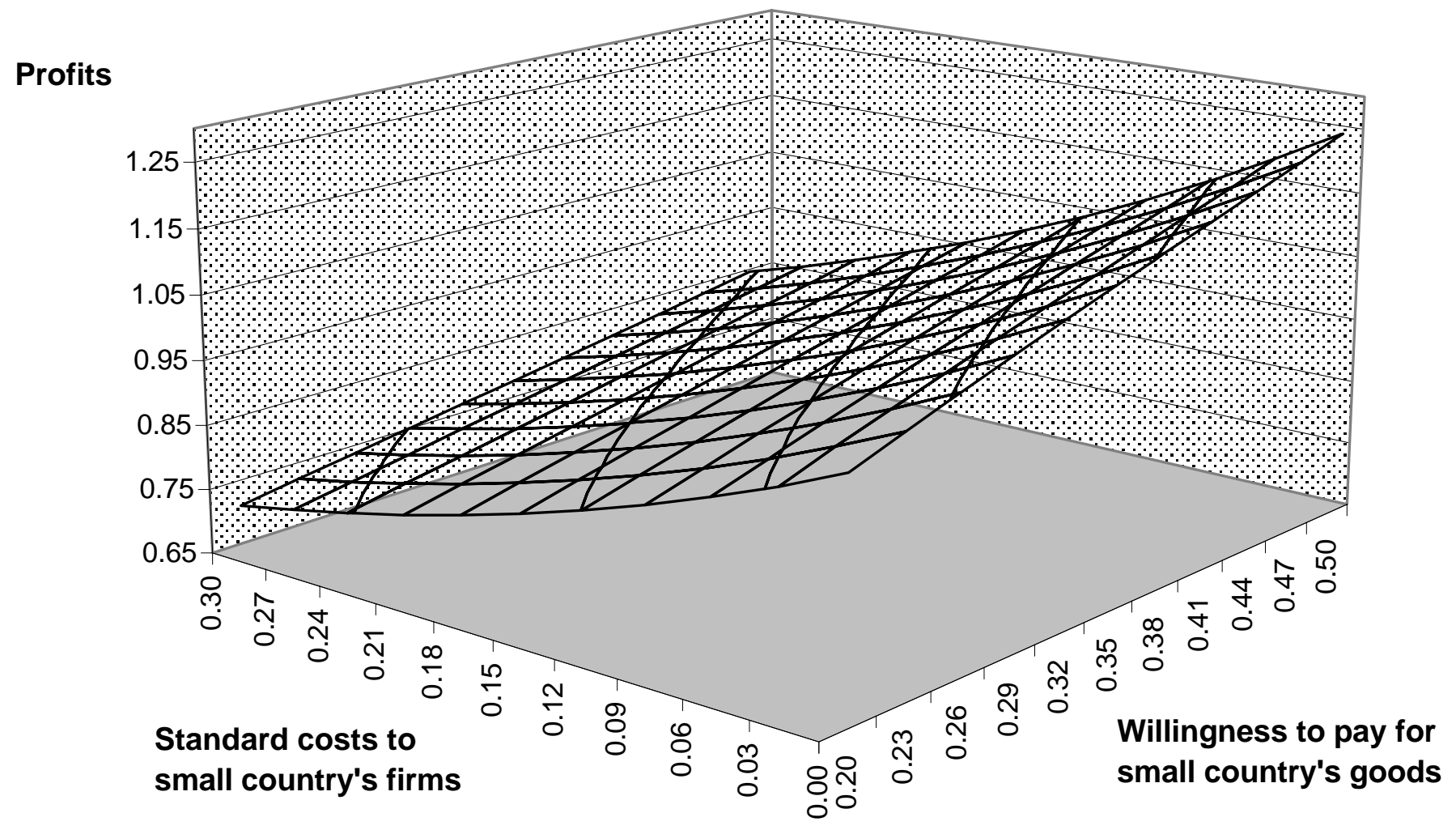

Figure 5B: Effect of a large-country standard on consumer welfare in the small country

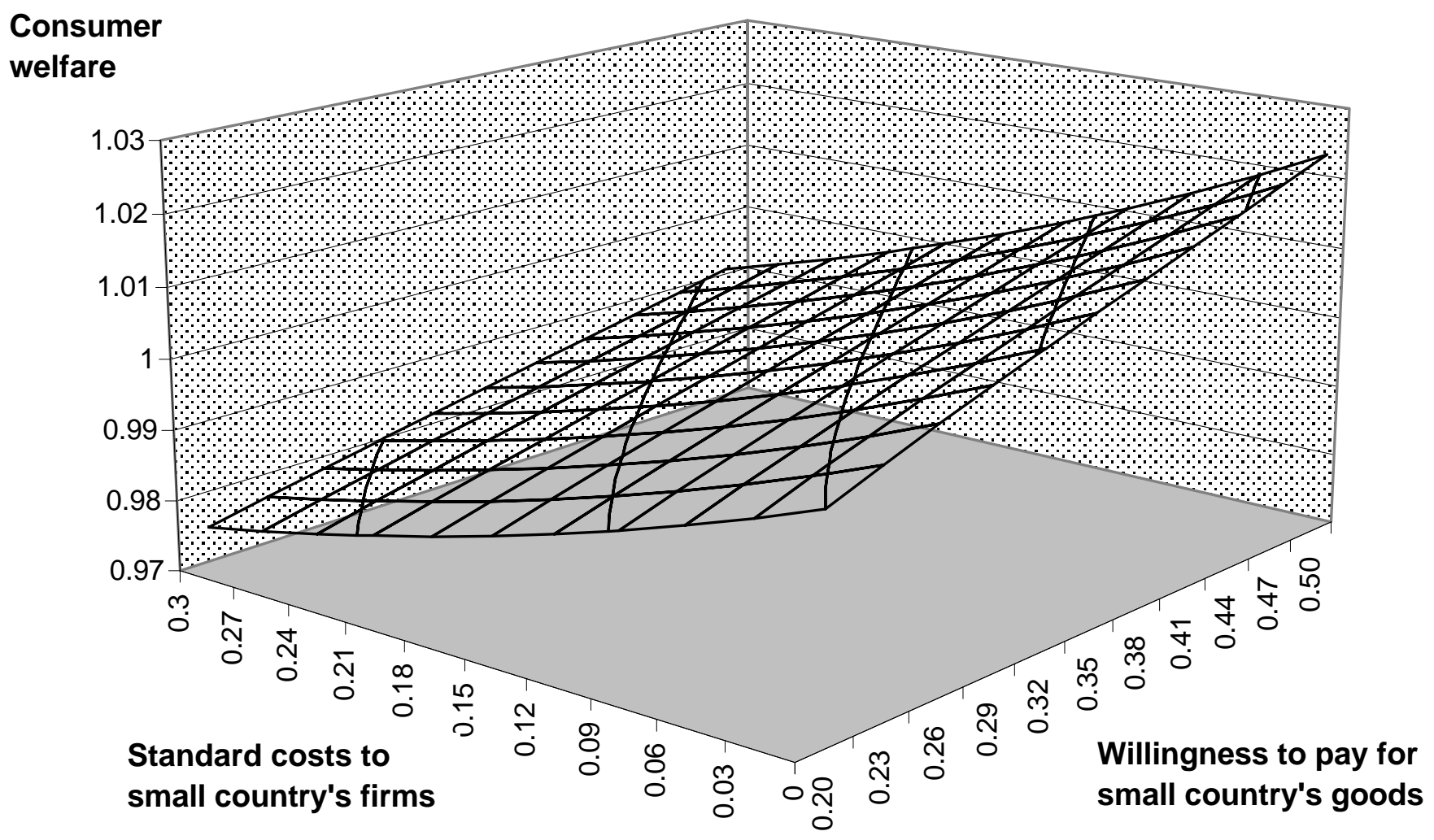


Figure 6A: Standards improve the substitutability between products

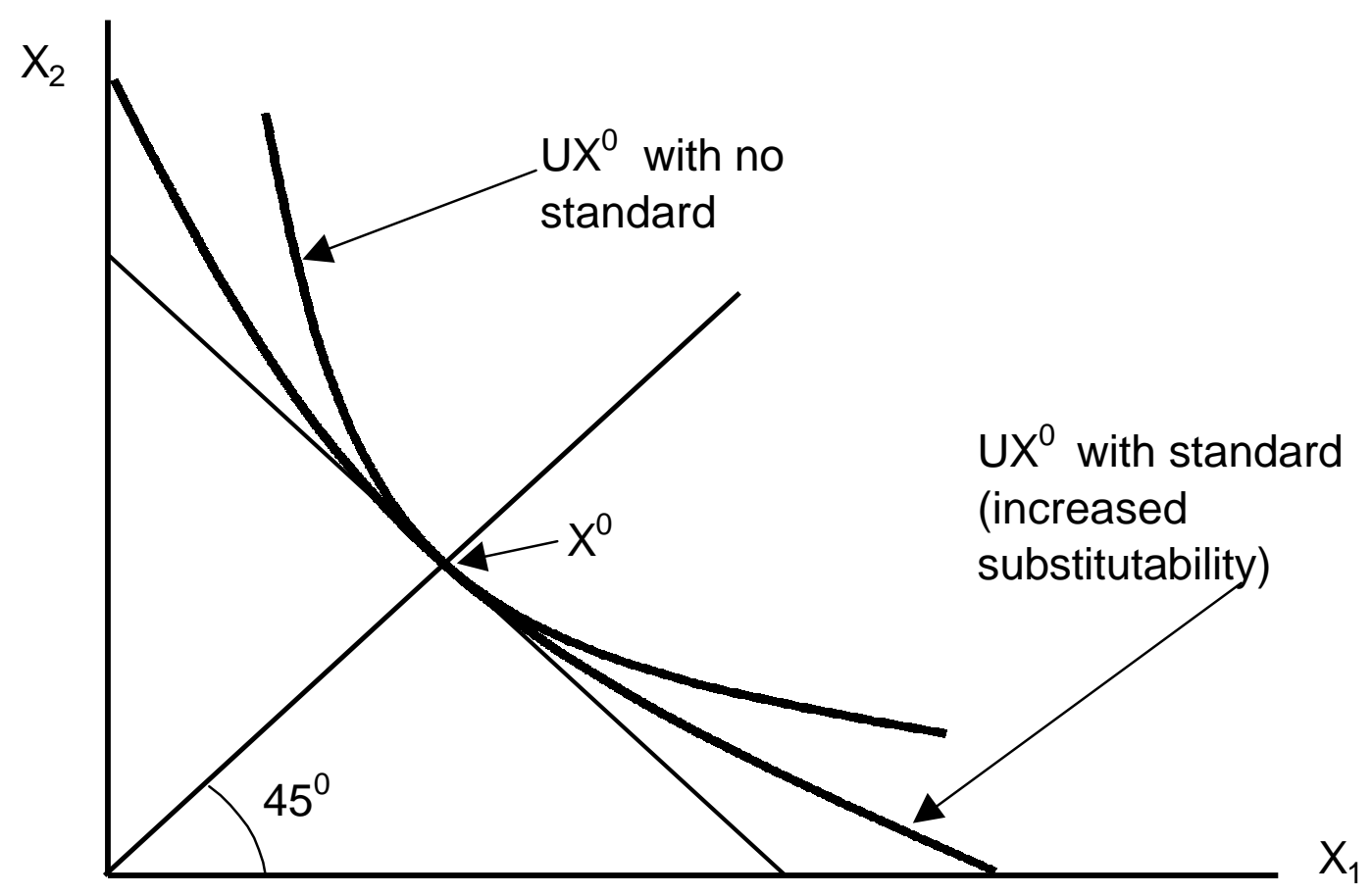

Figure 6B: Standards also alter cost or willingness to pay

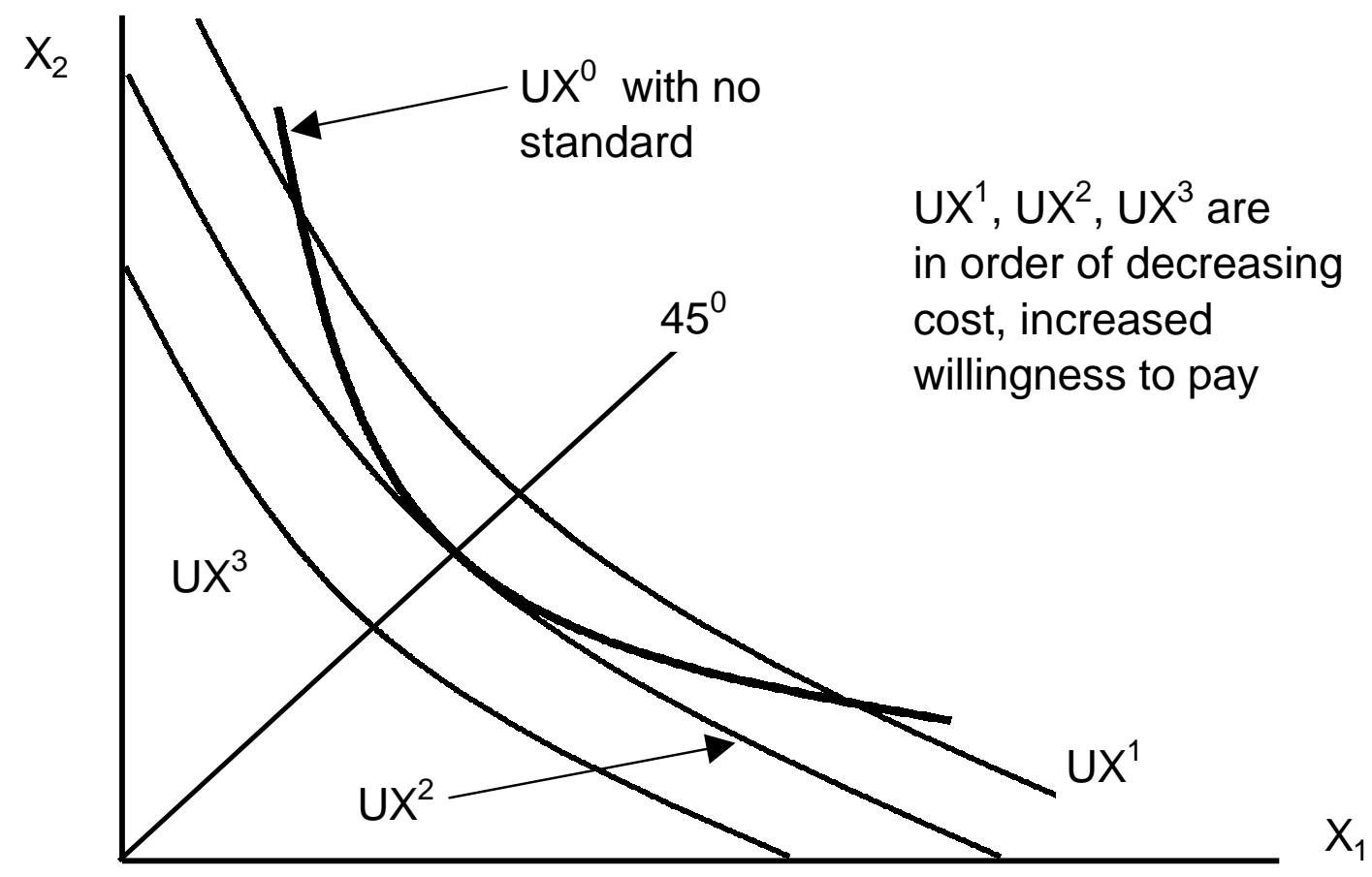


Figure 7A: Standards improve the complementarity between products

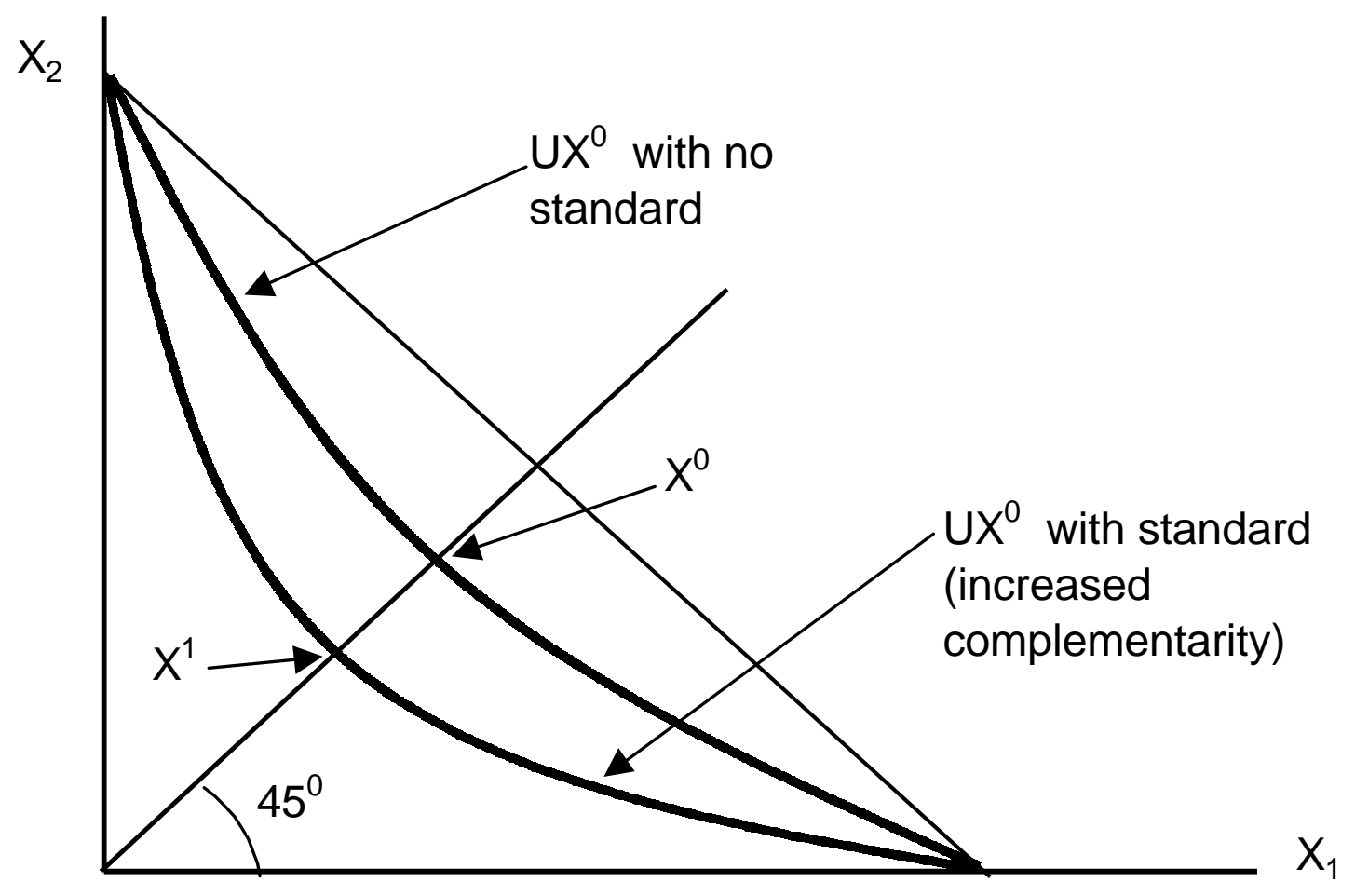

Figure 7B: Standards also alter cost or willingness to pay

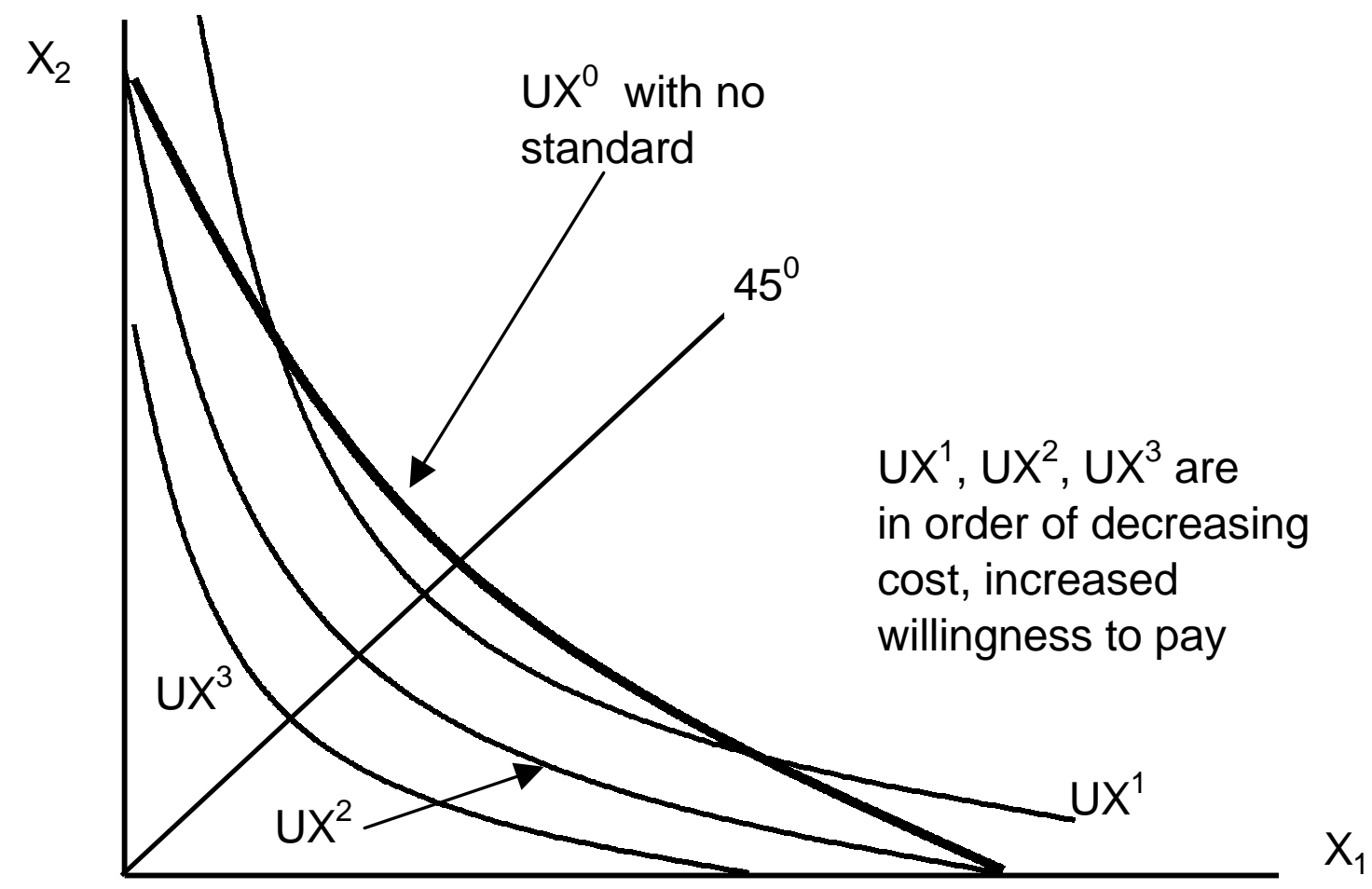


Figure 8A: Consumer welfare, standards improve substitutibility

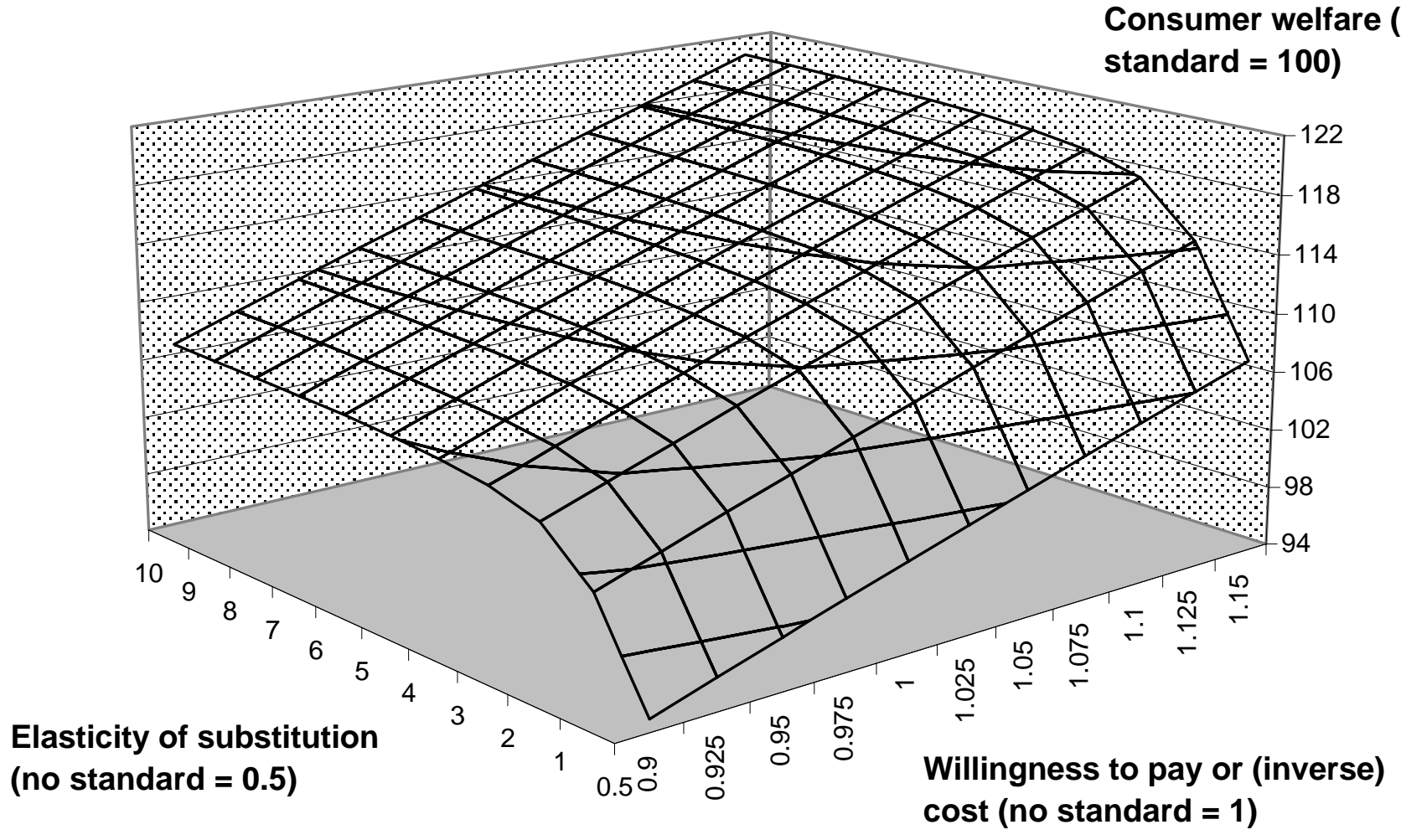

Figure 8B: Firm profits, standards improve substitutibility

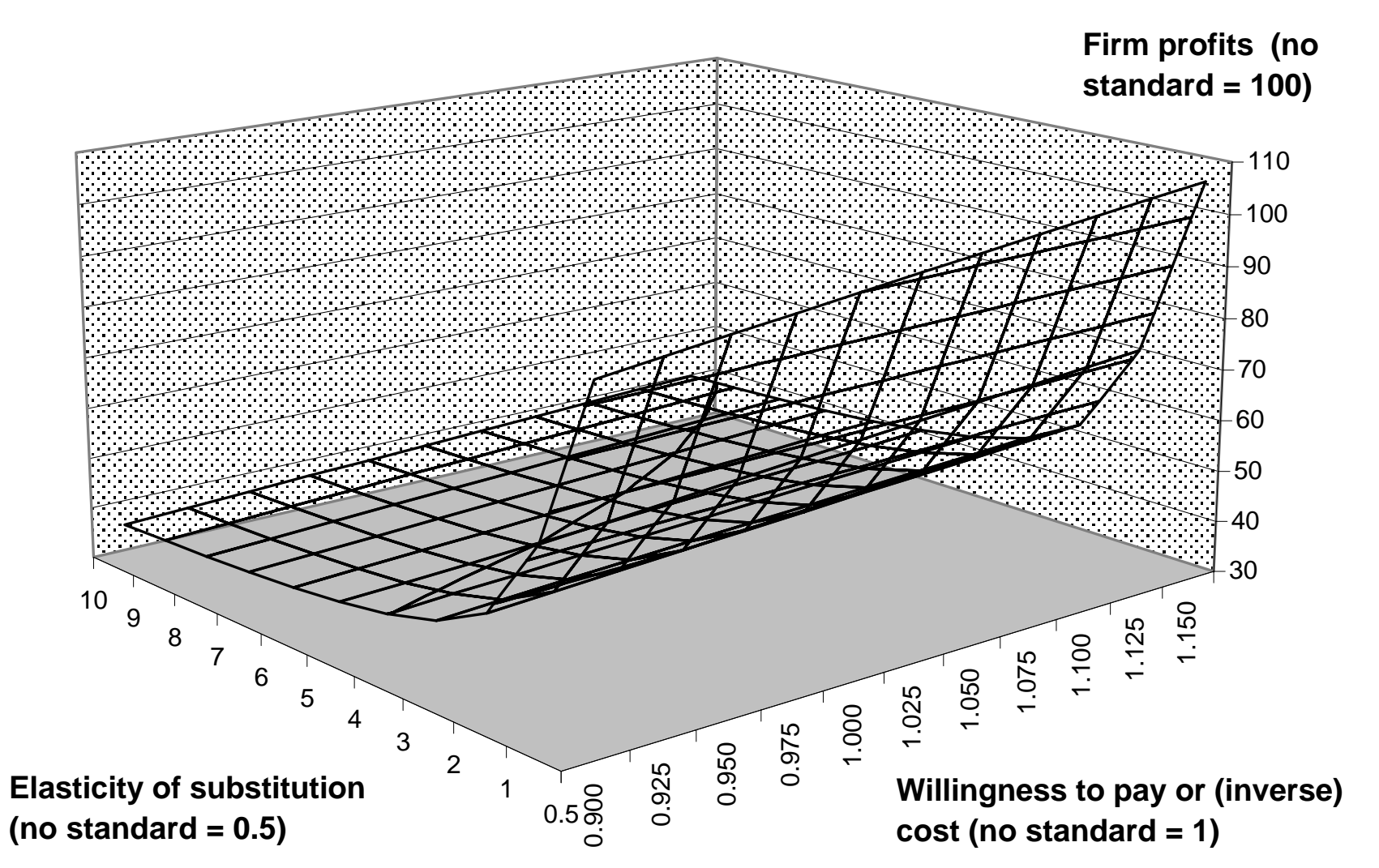


Figure 8C: Total welfare, standards improve substitutibility

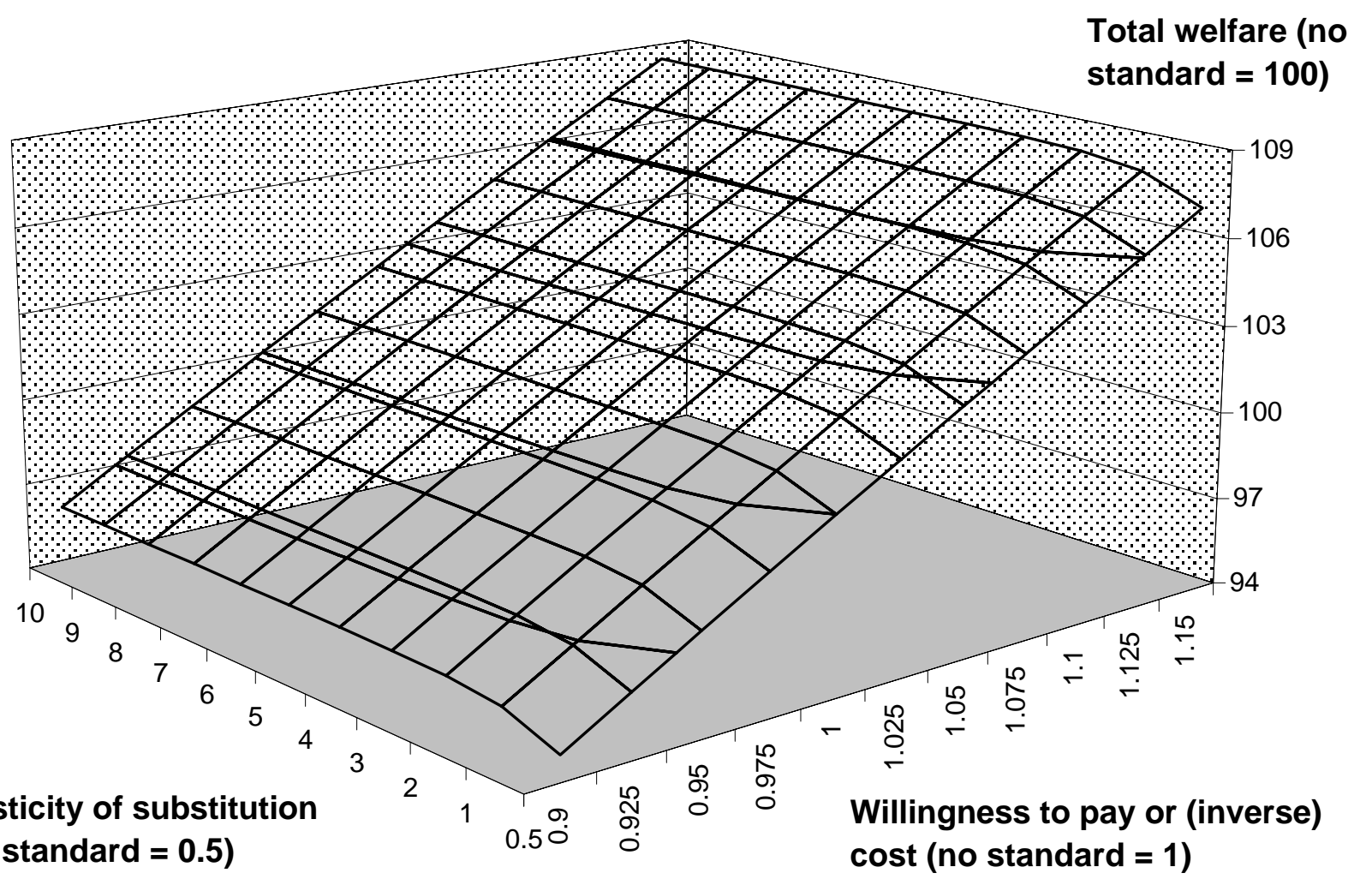


Figure 9A: Consumer welfare, standards improve complementarity

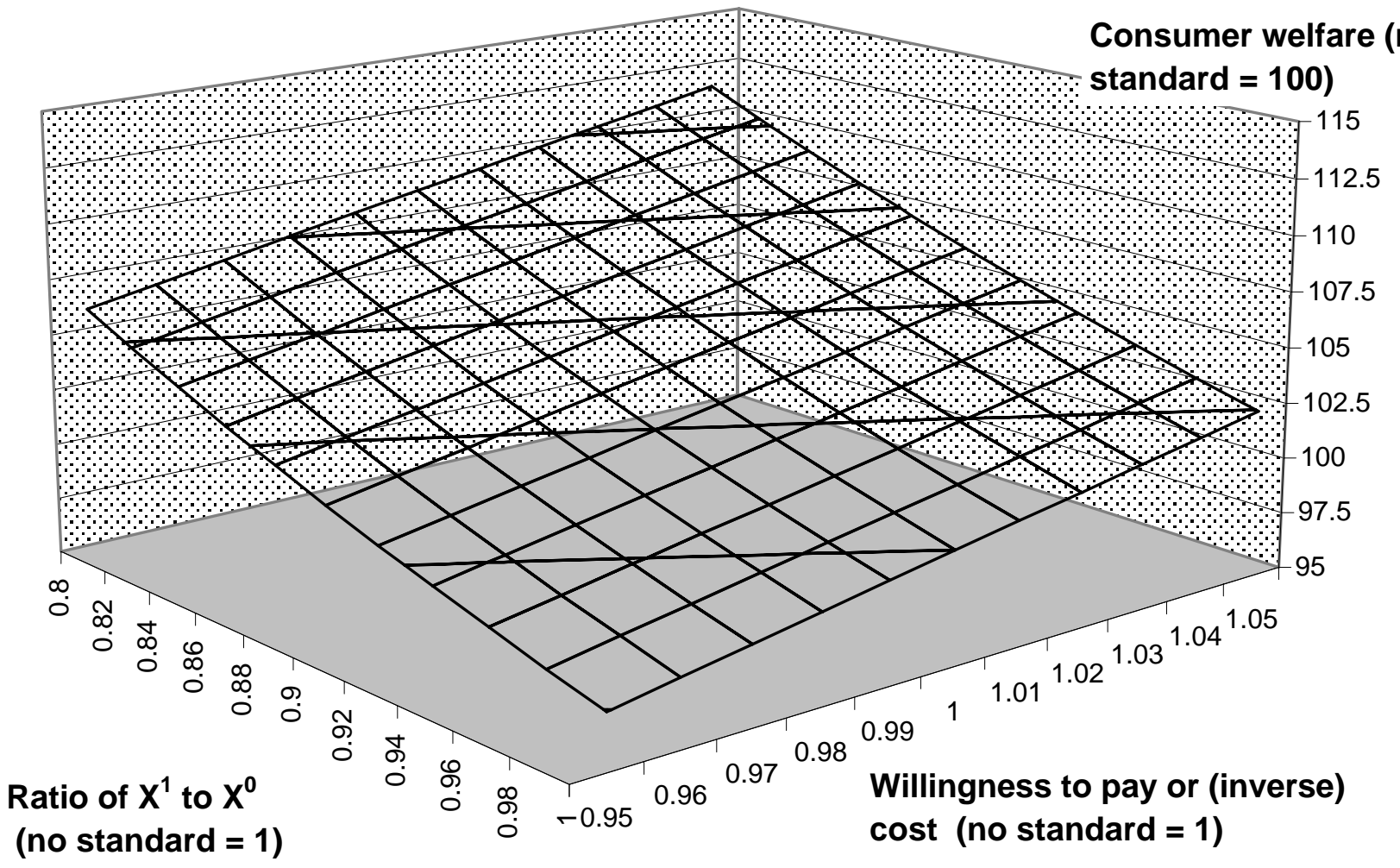

Figure 9B: Firm Profits, standards improve complementarity

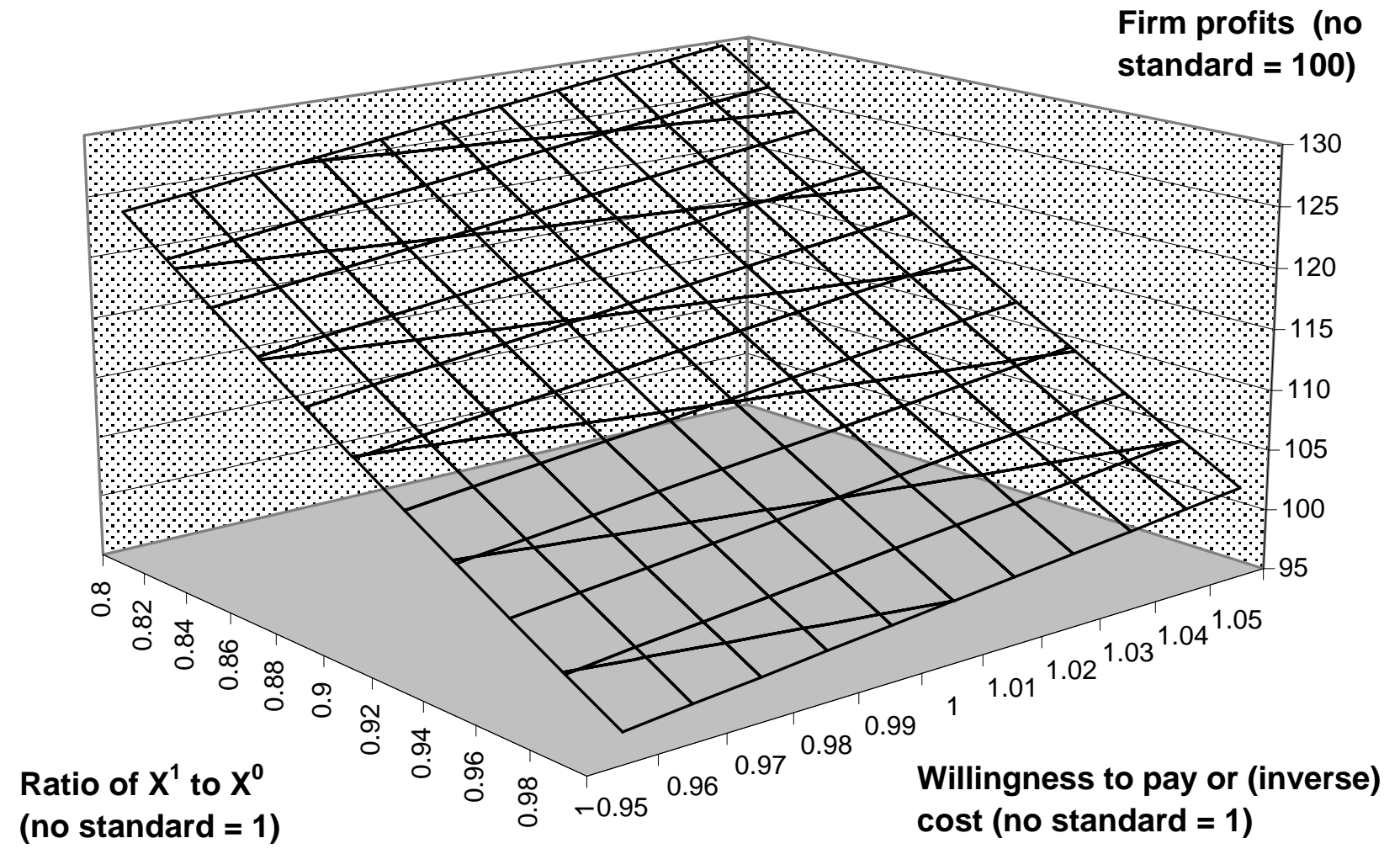




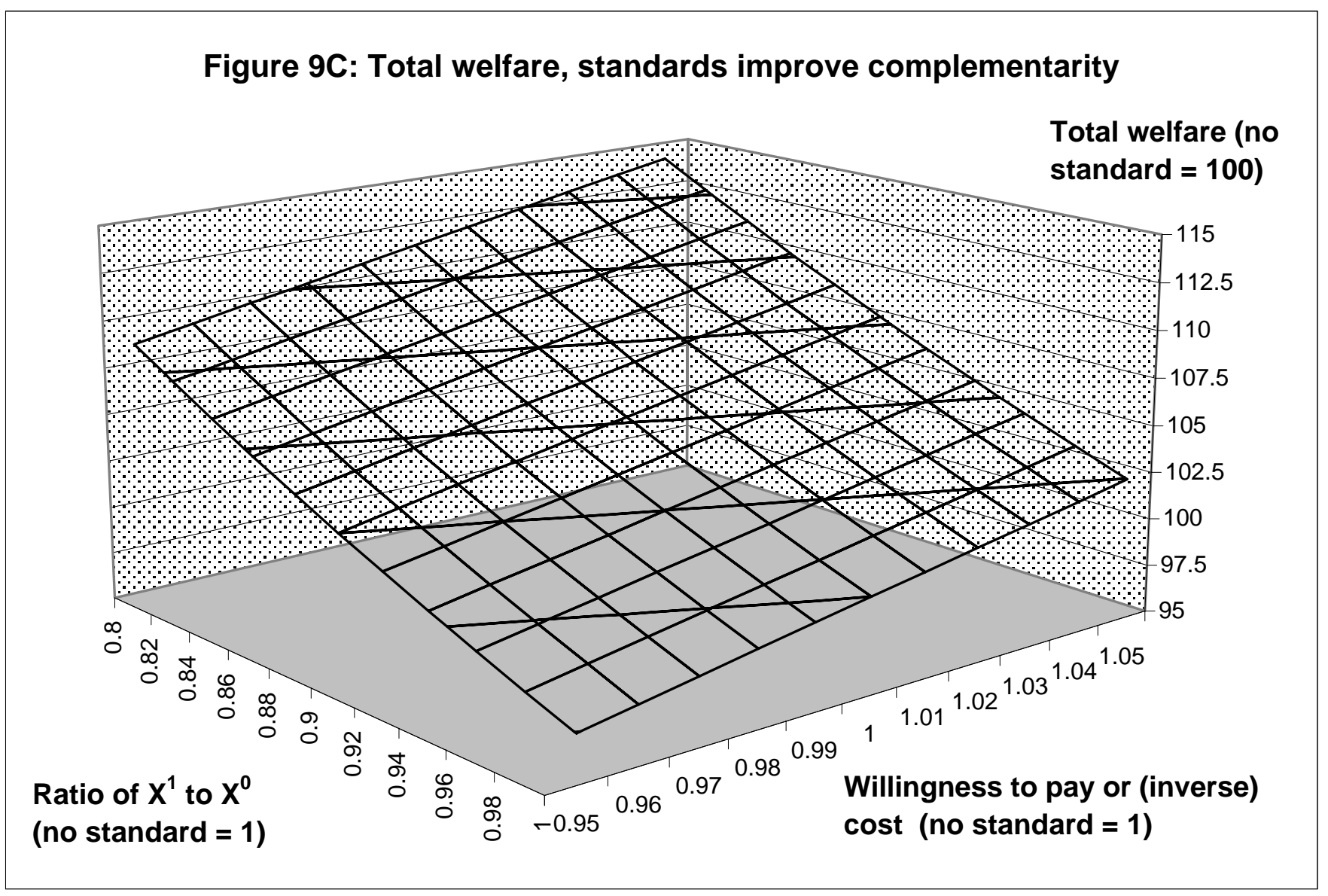


Figure 10. Individual arbitrage conditions

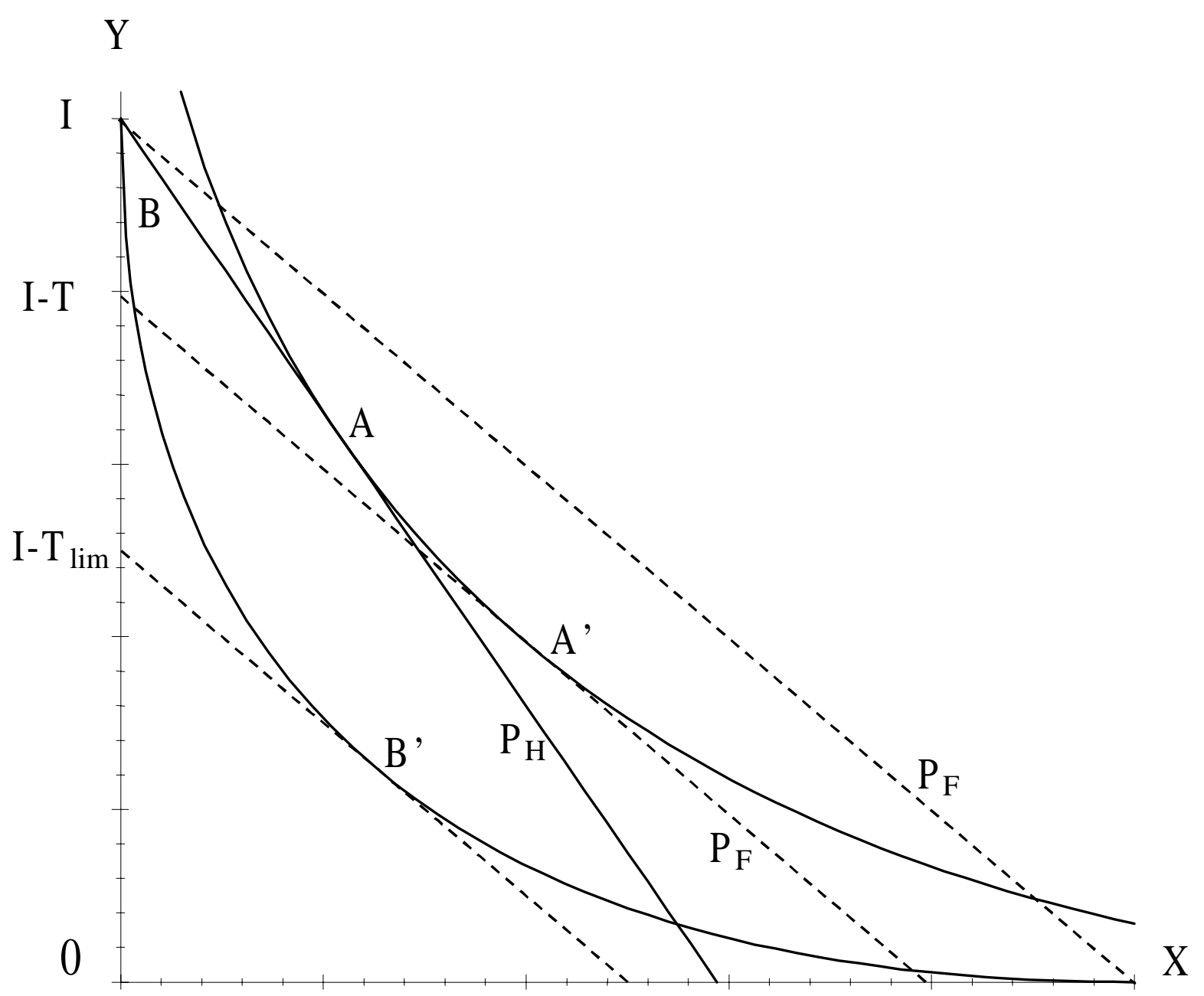





\section{Figure 11A. Price differential in an international monopoly}

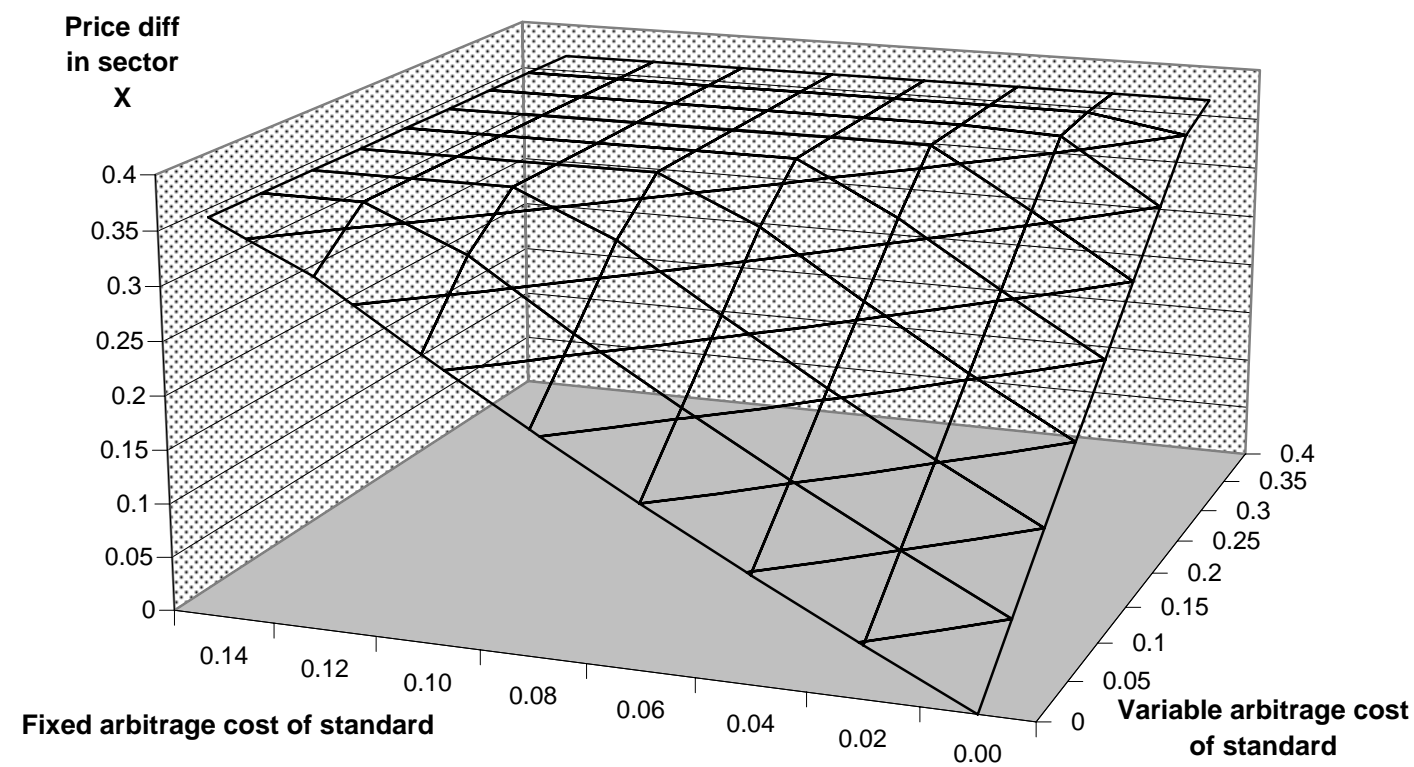

Figure 11B. Global welfare in an international monopoly

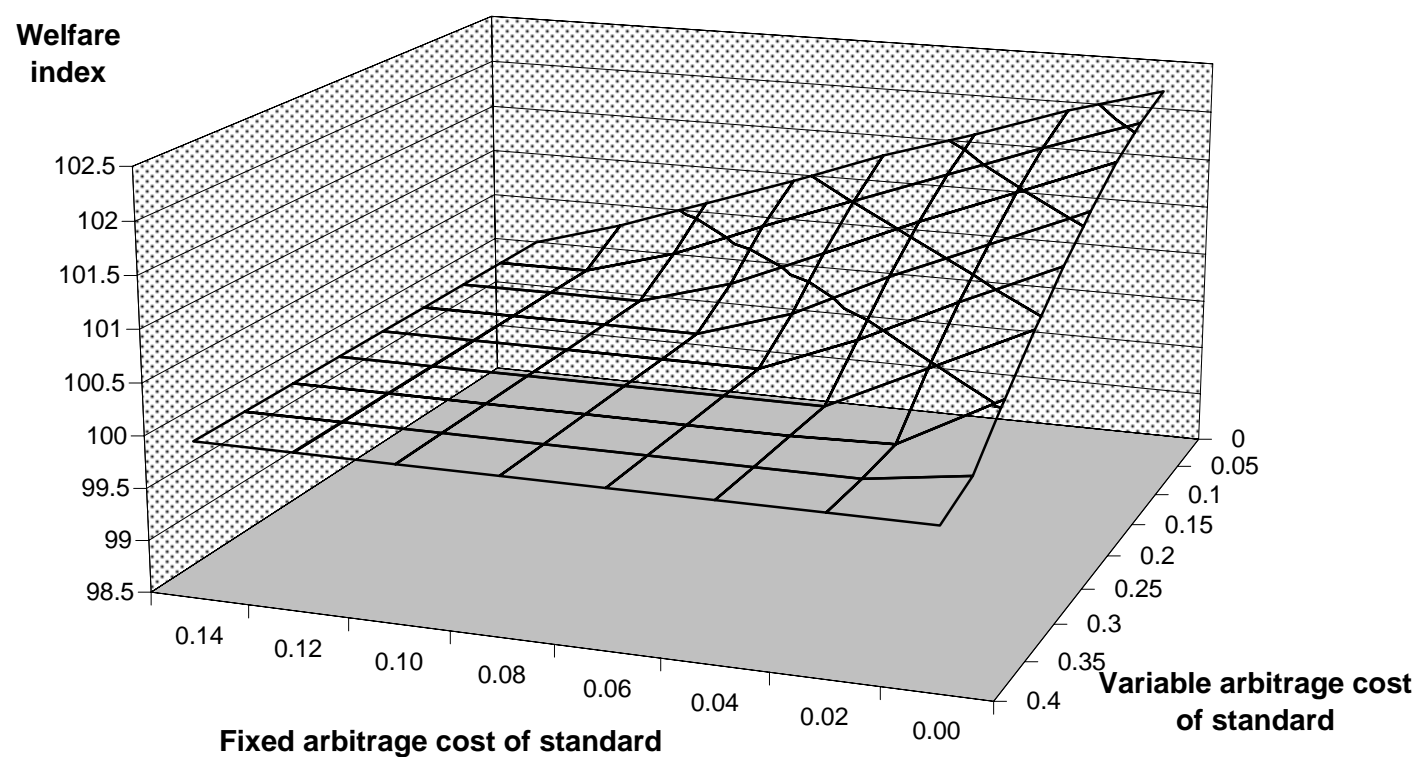



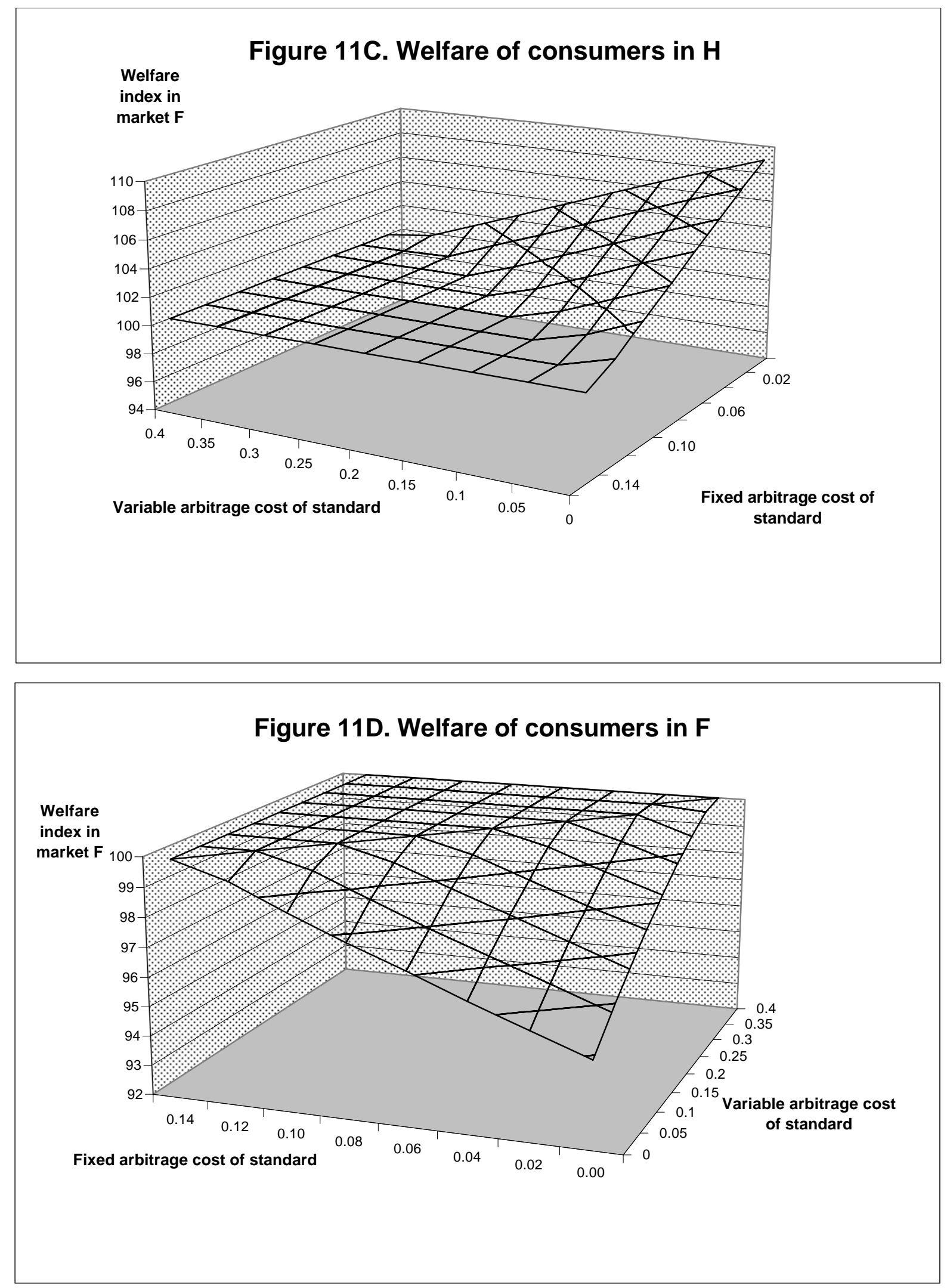
Figure 12A. Prices in a monopoly with trade and arbitrage costs (production in $F$, exports to $H$ )

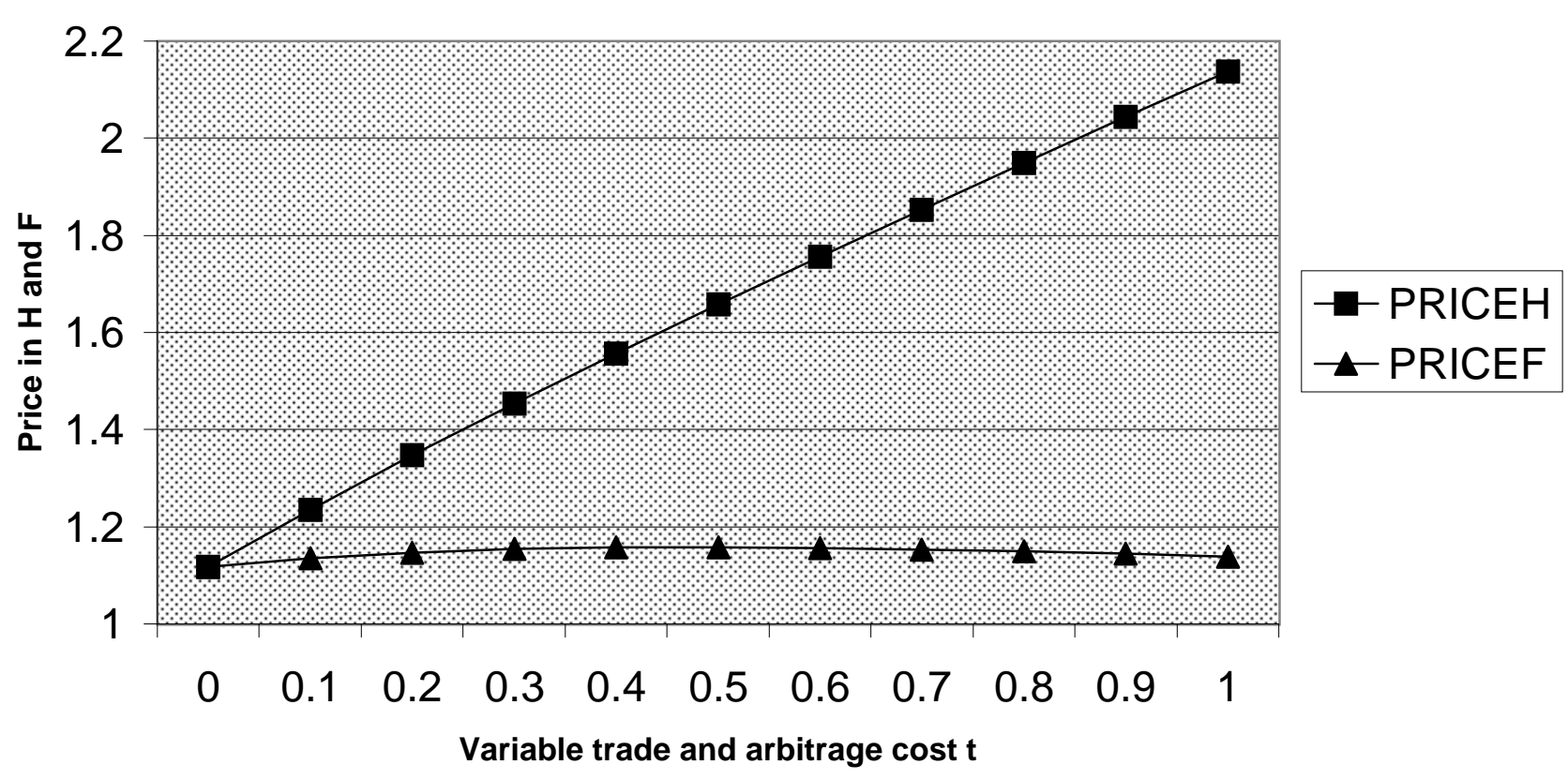

Figure 12B. Prices in a monopoly with trade and arbitrage costs (production in $\mathrm{H}$, exports to $\mathrm{F}$ )

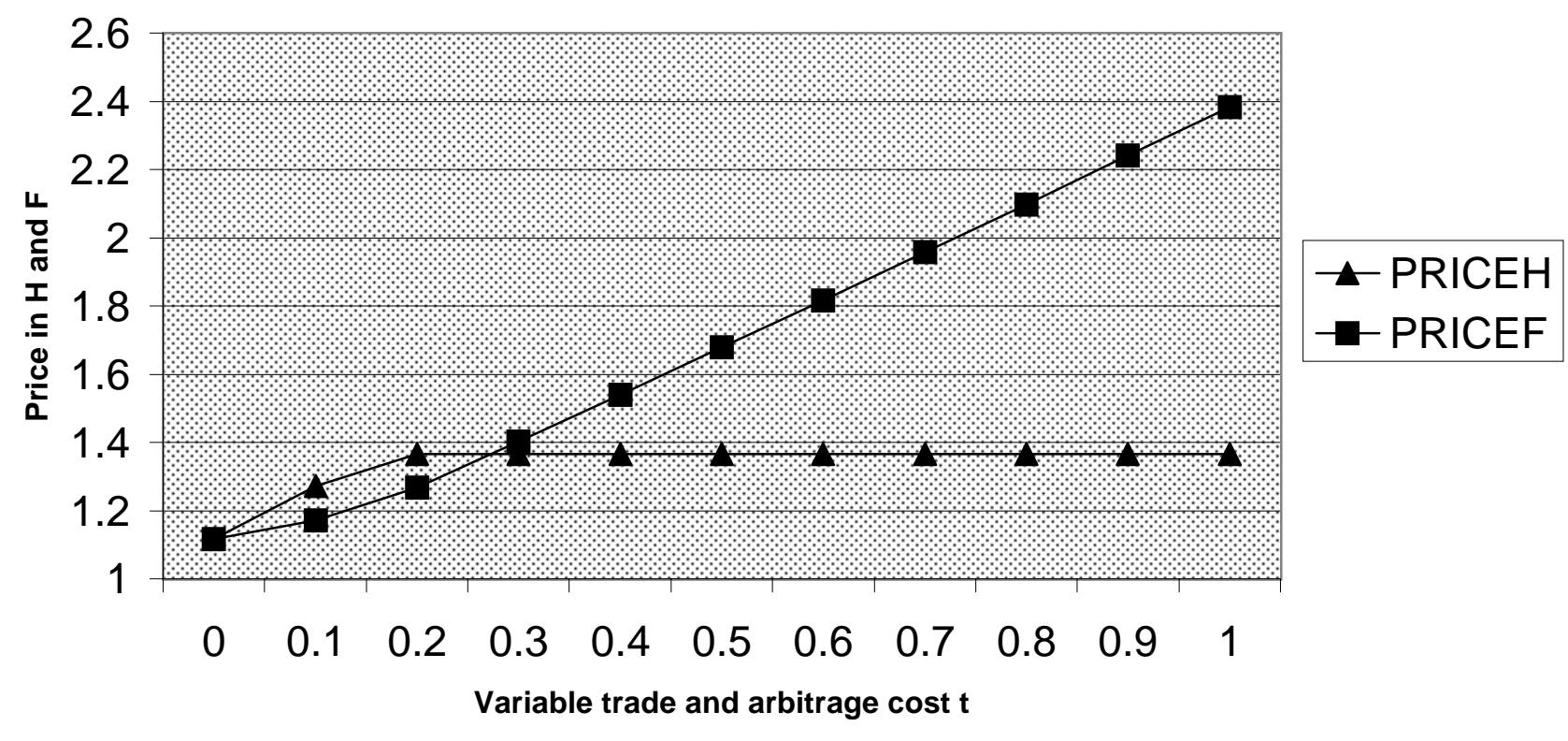



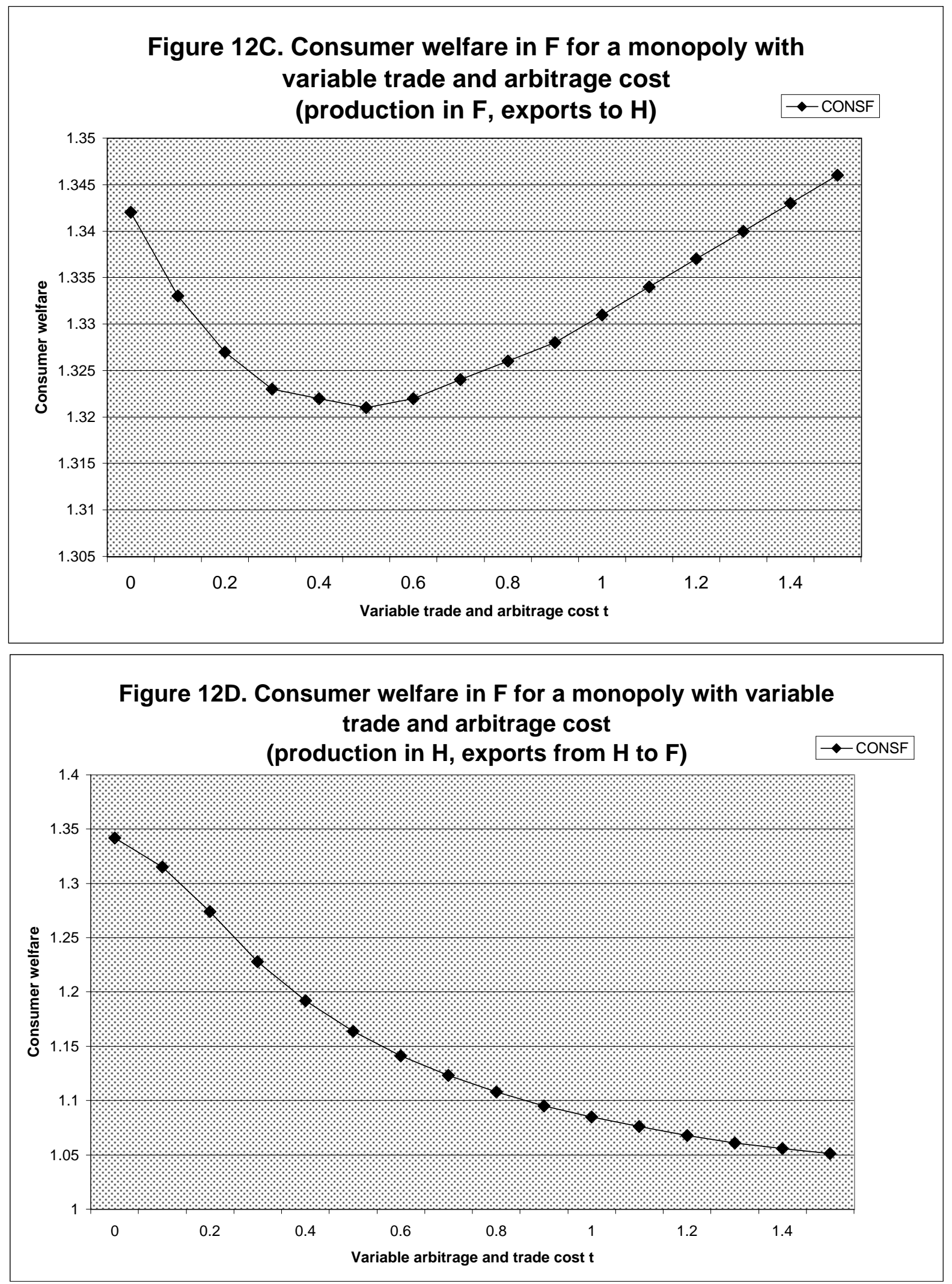

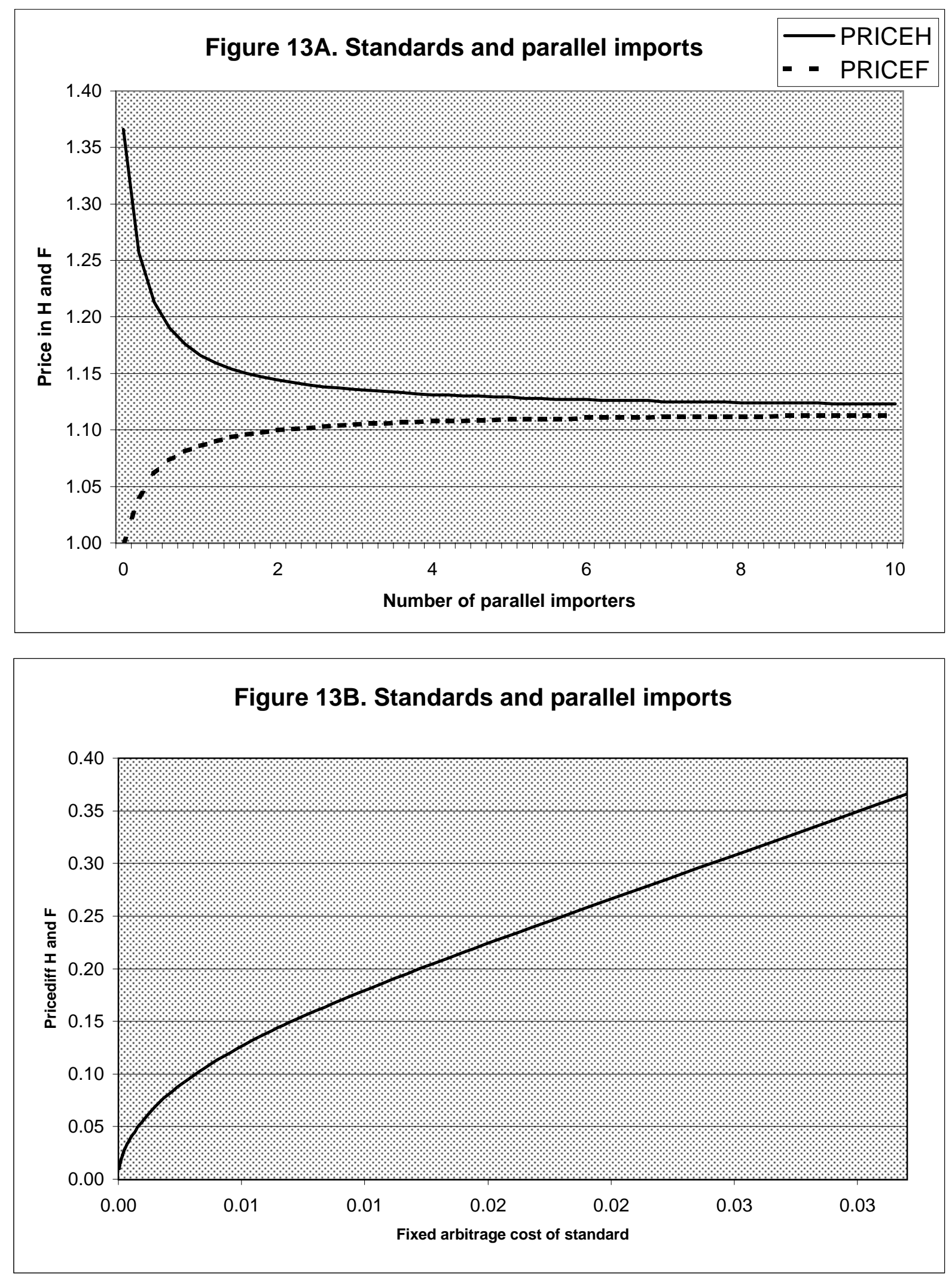


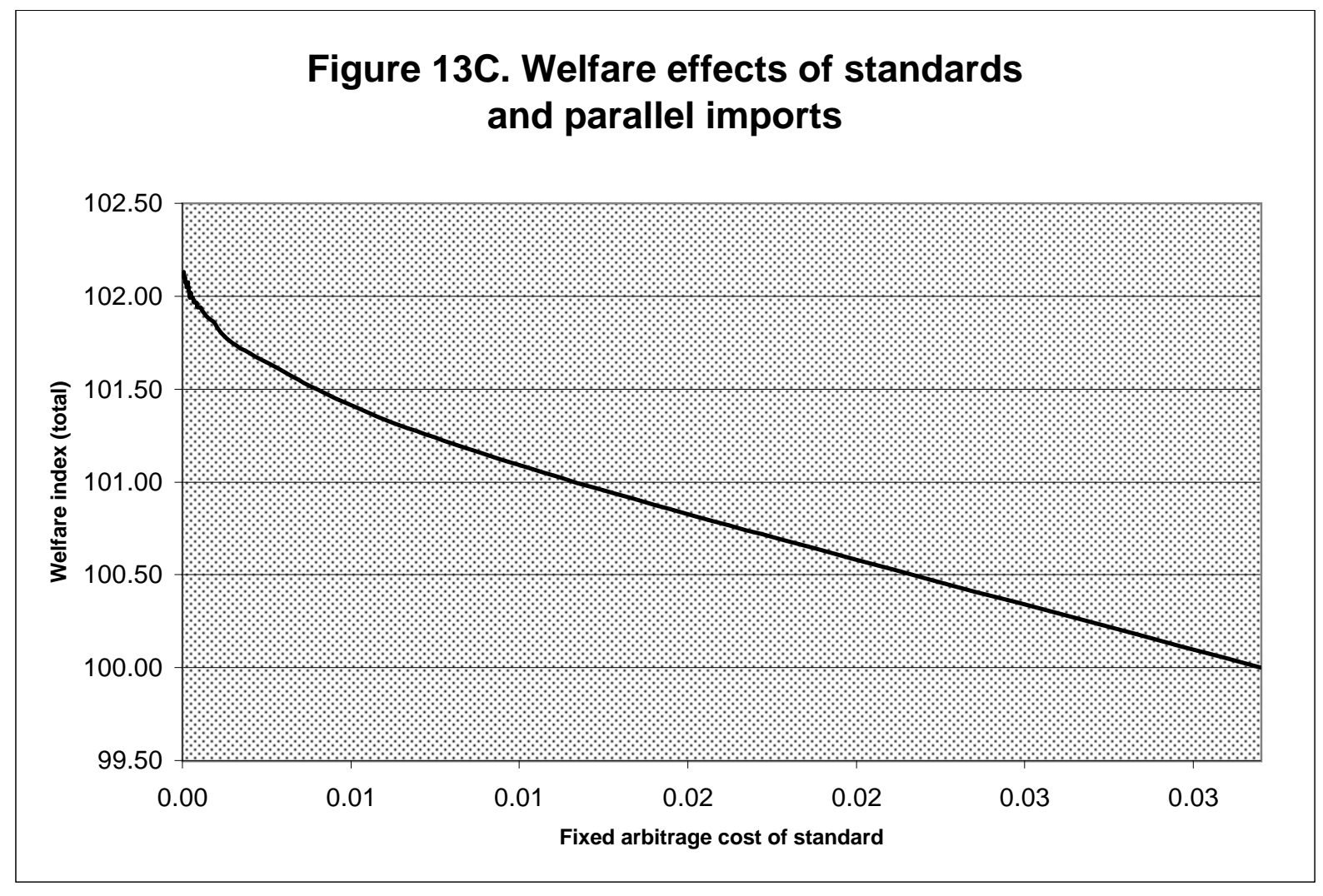



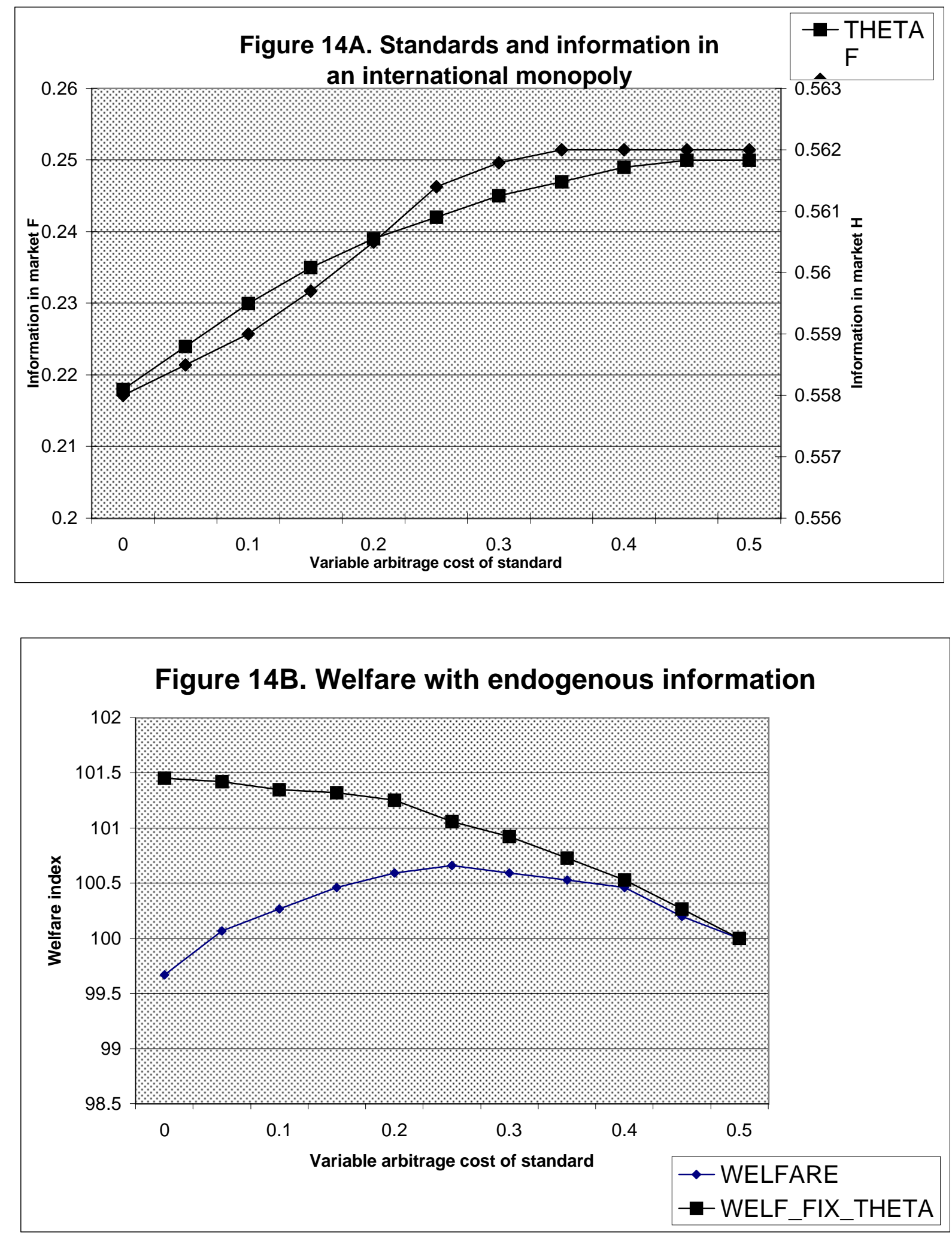

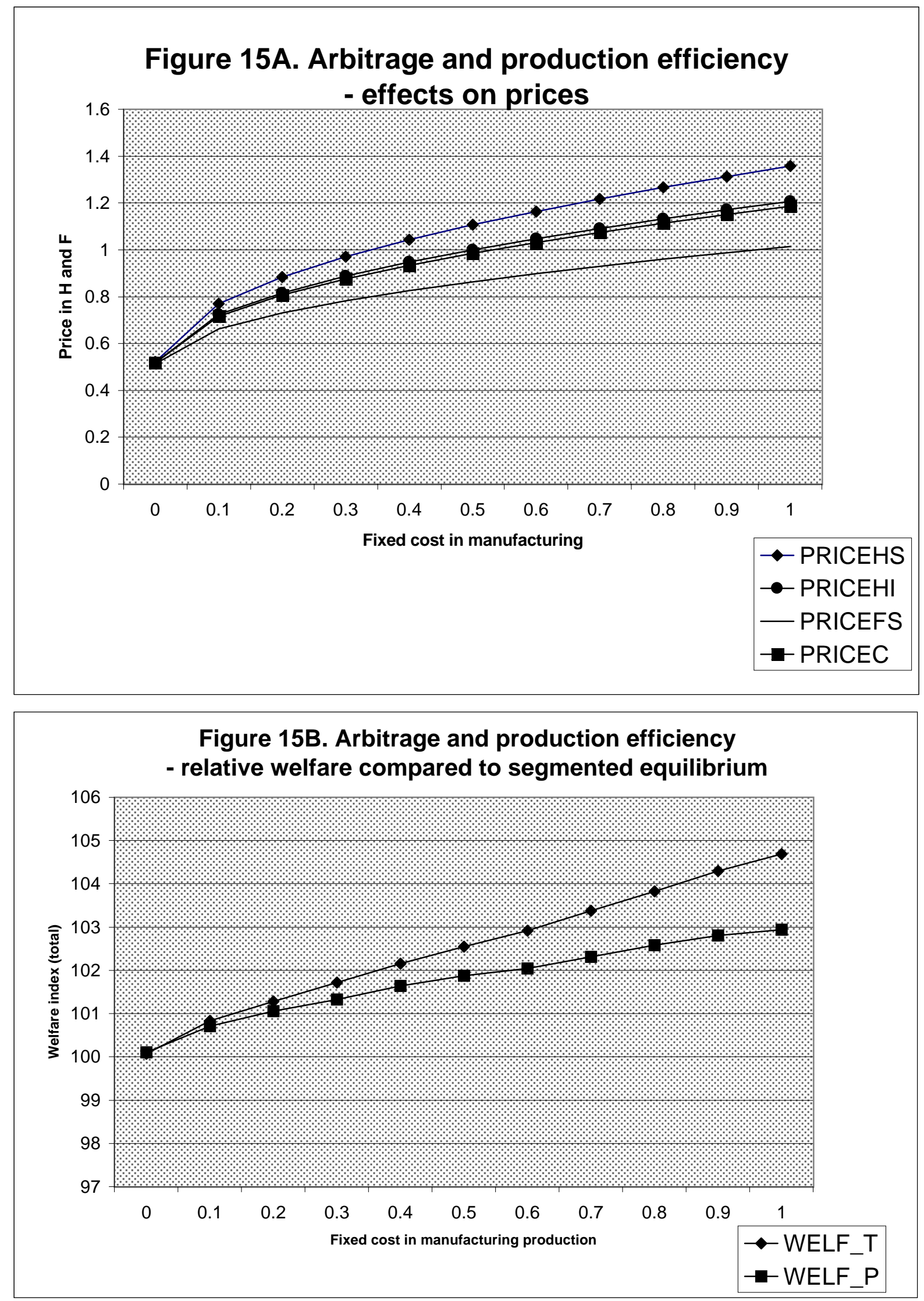

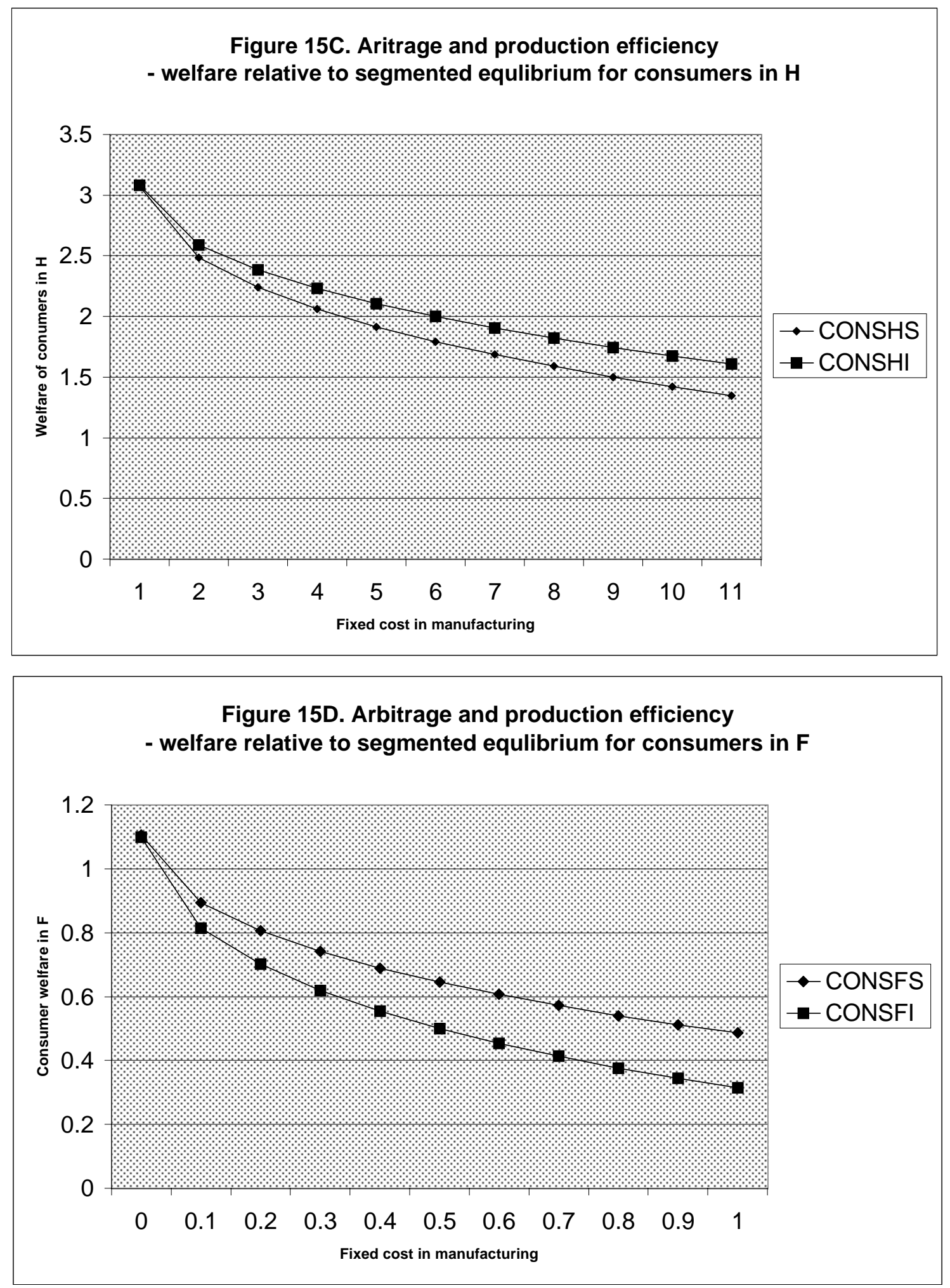